\title{
Paradigmenwechsel durch MiFID II: divergierende Anlegerleitbilder und neue Instrumentarien wie Qualitätskontrolle und Verbote
}

\author{
Prof. Dr. Thomas M. J. Möllers, Augsburg* \\ und \\ Mauritz Christopher Poppele, Augsburg**
}

Inhaltsübersicht

ZGR 2013, 437-481

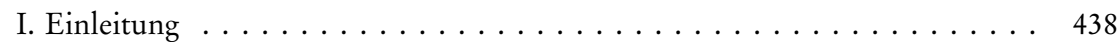

II. Anlegergleichbehandlung. . . . . . . . . . . . . . . . . . . . . . . . . 439

1. Regelungsziel . . . . . . . . . . . . . . . . . . . . . . 439

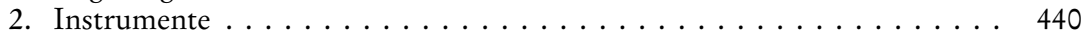

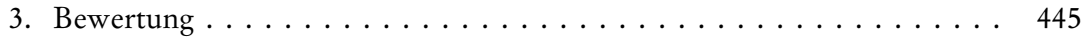

III. Rationale Anlegerentscheidung durch Aufklärung . . . . . . . . . . . . . . . 448

1. Regelungsziel . . . . . . . . . . . . . . . . . . . . . . 448

2. Instrumente . . . . . . . . . . . . . . . . . . . . . . 449

3. Bewertung ....................... 456

IV. Anlegerbezogene Beratung $\ldots \ldots \ldots \ldots \ldots \ldots \ldots \ldots \ldots \ldots \ldots$

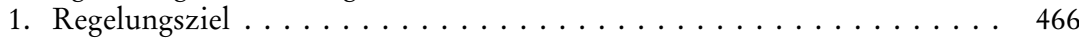

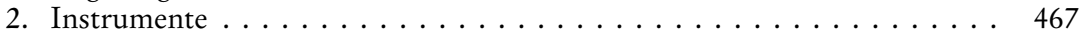

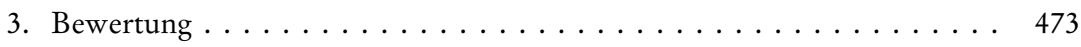

V. Professionelle Vermögensverwaltung . . . . . . . . . . . . . . . . 476

1. Regelungsziel . . . . . . . . . . . . . . . . . . . . . . . 476

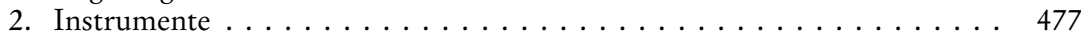

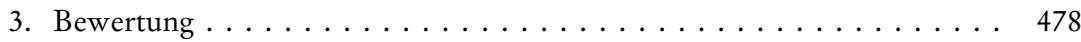

VI. Zusammenfassende Thesen . . . . . . . . . . . . . . . . . . . 479

Die einschlägigen Neuregelungen der MiFiD II und der AIFM-RiL bringen zablreiche Nenerungen mit sich. Zunehmend berücksichtigt der Gesetzgeber etwa die Probleme des information overload bei der Überarbeitung einzelner Informationspflichten. Zudem wird in immer stärkerem Maße auf eine gestaffelte Qualitätskontrolle und die Vermeidung von Interessenkonflikten und Produktverbote gesetzt. Die verschiedenen Maßnabmen lassen sich

* Dr. iur., Professor an der Universität Augsburg; Inhaber des Lehrstuhls für Bürgerliches Recht, Wirtschaftsrecht, Europarecht, Internationales Privatrecht und Rechtsvergleichung der Universität Augsburg, Geschäftsführender Direktor des Center for European Legal Studies (CELOS) sowie Inhaber eines Jean Monnet-Lehrstuhls ad personam.

* LL.M. (NYU), LL.M. (NUS), Wissenschaftlicher Mitarbeiter am Lehrstuhl für Bürgerliches Recht, Wirtschaftsrecht, Europarecht, Internationales Privatrecht und Rechtsvergleichung der Universität Augsburg. 
am besten strukturieren und bewerten, indem man zwischen den einzelnen Regelungszielen des Kapitalmarktrechts unterscheidet: Anlegergleichbehandlung, rationale Anlegerentscheidung durch Aufklärung, anlegerbezogene Beratung und professionelle Vermögensverwaltung. Dabei wird sich zeigen, dass die Konturierung des Anlegerleitbilds von dem jeweiligen Regelungszweck bestimmt wird und deshalb in Abstufungen divergiert.

The new MiFID II regime and the AIFM Directive bring about a variety of legislative novelties. The legislator increasingly considers the information overload problem when redesigning certain information duties. Moreover, the regulatory focus gradually shifts to staggered quality checks, the avoidance of conflicts of interest and product bans. In order to structure and evaluate these different measures, the following regulatory objectives need to be distinguished: equal treatment of investors, rational investor choice through education, investororiented advice and professional asset management. The following analysis will show that the relevant regulatory purpose defines the investor role model which diverges for this reason correspondingly.

\section{Einleitung}

Als vermeintliche Antwort auf die Finanzmarktkrise hatte der europäische Gesetzgeber bereits mit der AIFM-Richtlinie ${ }^{1}$ eine Gesetzgebungsmaschinerie in Gang gesetzt, deren Höhepunkt mit den Vorschlägen zur Neufassung der MiFID I ${ }^{2}$ der Kommission ${ }^{3}$ vom Oktober 2011 und des EU-Parlaments ${ }^{4}$ vom Oktober 2012 sowie der dazugehörigen Verordnung ${ }^{5}$ noch bevorsteht. Auf nationaler Ebene wurde bereits die Entscheidung getroffen, das InvG durch ein neues Kapitalanlagegesetzbuch $(\mathrm{KAGB})^{6} \mathrm{zu}$ ersetzen und auch für das WpHG zeichnet sich umfassender Reformbedarf ab. Trotz dieser unaufhaltsamen Europäisierung des Kapitalmarktrechts ist das Verhältnis der nationalen Zivilrechtsprechung zum Europarecht noch immer ungeklärt. Der Gesetzgeber greift in immer stärkerem Maße in die Marktwirtschaft ein, indem er Informationen, Mitarbeiter und Finanzprodukte der Qualitätskontrolle unterzieht. Anstatt wie bisher auf umfassende Informationspflichten zu

1 RiL 2011/61/EU v. 8. 6. 2011, ABl. EU Nr. L 174, S. 1 („AIFM-RiL“).

2 RiL 2004/39/EG v. 21.4. 2004, ABl. EU Nr. L 145, S. 1 („MiFID I“).

3 Vorschlag für eine RiL über Märkte für Finanzinstrumente zur Aufhebung der RiL 2004/39/EG (Neufassung) v. 20.10. 2011, KOM(2011) 656 endg. („MiFID II-E“).

4 Abänderungen des Europäischen Parlaments v. 26.10.2012 zu dem Vorschlag für eine RiL über Märkte für Finanzinstrumente zur Aufhebung der RiL 2004/39/EG, P7_TAPROV(2012)0406 („MiFID II-E (EUP)“).

5 Vorschlag für eine Verordnung über Märkte für Finanzinstrumente und zur Änderung der Verordnung [EMIR] über OTC-Derivate, zentrale Gegenparteien und Transaktionsregister v. 20. 10.2011, 2011/0296 (COD) („MiFIR-E“); Abänderungen des Europäischen Parlaments v. 26.10.2012, P7_TA-PROV(2012)0407 („MiFIR-E (EUP)“).

6 RegE z. KAGB v. 21.12. 2012, BR-Drucks. 791/12. Hierzu Möllers, Das Kapitalanlagegesetzbuch, 2013 (im Erscheinen). 
vertrauen, wird verstärkt auf ex ante-Qualifikationen, Vermeidung von Interessenkonflikten und Verbote gesetzt.

Im Folgenden werden die einschlägigen Neuregelungen vorgestellt und darüber hinaus die Regelungsziele des Anlegerschutzes dargestellt. So ist zwischen Anlegergleichbehandlung (II.), rationale Anlegerentscheidung durch Aufklärung (III.), anlegerbezogene Beratung (IV.) und professionelle Vermögensverwaltung (V.) zu unterscheiden. Mit dieser Strukturierung lassen sich die dazugehörigen Regelungsinstrumentarien wie Information, Qualitätskontrolle und Verbote dogmatisch einordnen und bewerten. Dabei wird sich zeigen, dass das Anlegerleitbild von dem jeweiligen Regelungszweck bestimmt wird und deshalb divergiert. Ausgespart wird die Frage, ob sich der Anlegerschutz hin zum Verbraucherschutz entwickelt. ${ }^{7}$

\section{Anlegergleichbebandlung}

\section{Regelungsziel}

Die Anlegergleichbehandlung als Regelungsziel ist eng mit der institutionellen Funktionsfähigkeit der Kapitalmärkte verwoben: Typischerweise verfügen Anleger nicht über eigene Informationen, um die Chancen und Risiken einer Anlage beurteilen zu können. ${ }^{8}$ Kursrelevante Informationsvorsprünge der Emittenten und einzelner Insider gegenüber der Anlegergesamtheit haben potentiell zur Folge, ${ }^{9}$ dass sich am Markt nicht der optimale Produktpreis bilden kann; es drohen Marktineffizienzen und Marktversagen. ${ }^{10} \mathrm{Zu}$ den ökonomischen Grundbedingungen eines funktionierenden Kapitalmarkts zählt daher die ausreichende Informationsversorgung der Anleger. ${ }^{11}$ Die institutionelle Funktionsfähigkeit bedingt darüber hinaus, dass die Anleger Vertrauen in die Integrität des Kapitalmarkts haben. ${ }^{12}$ Die Anlegergleichbehandlung erfordert insofern zweierlei: Alle Marktteilnehmer müssen zum möglichst

7 Bspw. jüngst Buck-Hees, ZHR 177 (2013), 310, 340 ff, 343; DIEs., ZHR 176 (2012), 66 ff; Mülbert, ZHR 177 (2013), 160, 180 f; Koller, in: Assmann/Schneider, WpHG, 6. Aufl., 2012, \$31 Rdn. 4 ff; Moloney, 13 EBOR, 169 ff (2012); Dies., 63 Current Legal Problems, 375 ff (2010); Kingsford SMith, in: Howells/Ramsay/Wilhelmsson/Kraft (Hrsg.), Handbook of Research on International Consumer Law, 2010, S. $431 \mathrm{ff}$.

8 Lenenbach, Kapitalmarktrecht, 2. Aufl., 2010, Rdn. 11.3.

9 Möllers, ZGR 1997, 334, 338; zuvor bereits Косн/Sснміdт, BFuP 1982, 231, 232 f.

10 Fleischer, Informationsasymmetrien im Vertragsrecht, 2001, S. 121 ff; DERs., Gutachten F z. 64. DJT, 2002, S. 23; vgl. allgemein auch KaHnert, Rechtsetzung im Europäischen Gesellschaftsrecht, 2012, S. 35 ff. Grundlegend AkerLof, 84 Q.J. Econ., $488 \mathrm{ff}$ (1970).

11 Lenenbach, aaO (Fn. 8), Rdn. 11.41.

12 Bspw. RegE z. AnsFuG v. 8.11.2010, BT-Drucks. 17/3628, S. 1; EuropäIscher WIRTschafTs- Und SozIalausschuss, Stellungnahme z. Vorschlag der Marktmissbrauch- 
gleichen Zeitpunkt über Zugang zu denselben bewertungsrelevanten Informationen verfügen ${ }^{13}$ und für die Veröffentlichung unrichtiger oder unvollständiger Informationen sind Kompensations- und Sanktionsmechanismen vorgesehen.

\section{Instrumente}

\section{a. Informationelle Gleichbehandlungspflichten}

Informationelle Gleichbehandlungspflichten richten sich primär an den Kapitalmarkt. Aus diesem Grund werden die Pflichten zur Emissions- ( $\mathbb{\$} 3 \mathrm{ff}$ WpPG), Ad hoc- ( $\$ 15 \mathrm{WpHG})$, Directors' Dealings- ( $\$ 15$ a WpHG), Beteiligungs- ( $\mathbb{S} 21 \mathrm{ff} W \mathrm{pHG})$, Regel- (\$\$ $37 \mathrm{vff} W \mathrm{pHG}$ ) und Übernahmepublizität $(\mathbb{S} 10,14,23$ WpÜG) und zur Information der Wertpapierinhaber $\left(\mathbb{S} 30\right.$ a ff WpHG) als marktbezogene ${ }^{14}$ Informationspflichten bezeichnet.

\section{b. Kompensatorische Gleichbehandlungspflichten}

Institutioneller und individueller Anlegerschutz sind oft „zwei Seiten derselben Medaille" ${ }^{15}$ Schließlich sind auch die Interessen des einzelnen Anlegers zu schützen, um das Vertrauen in die Kapitalmarktintegrität sicherzustellen. ${ }^{16}$ Hierauf zielen beispielsweise Vorschriften zur kompensatorischen Gleichbehandlung der einzelnen Anleger ab, wie etwa das Pflichtangebot gem. $\$ 35$ Abs. 2 WpÜG. Nach Kontrollerlangung über die Zielgesellschaft (\$29 Abs. 2 WpÜG) wird der Erwerber dazu verpflichtet, den verbleibenden Anlegern die Übernahme ihrer Anteile anzubieten. Regelmäßig geht dem Kontrollerwerb der Kauf eines größeren Aktienpakets voraus, wofür den Veräußerern ein zusätzlicher Bonus gezahlt werden muss. ${ }^{17}$ An diesem Kontrollbonus sollen auch die verbliebenen Anleger partizipieren. ${ }^{18}$ Das Pflichtangebot konkreti-

VO und z. Vorschlag für eine Marktmanipulations-RiL v. 28.3.2012, ECO/322, Rdn. 3.1.

13 Lenenbach, aaO (Fn. 8), Rdn. 11.4.ff.

14 Der Begriff geht zurück auf Vogel, Vom Anlegerschutz zum Verbraucherschutz, 2005, S. 22; übernommen von Lenenbach, aaO (Fn. 8), Rdn. 11.12.

15 So Hopt, ZHR 159 (1995), 135, 159; ebenso Köndgen, FS Druey, 2002, S. 791, 799 m. Fn. 48; Möllers/Leisch, ZIP 2002, 1995, 1997; Dies., BKR 2001, 78, 79 m. Fn.14; Fuchs/DüHn, BKR 2002, 1063, 1065. Präzisierend jüngst MüLbert, ZHR 177 (2013), 160, 177.

16 S. Норт, ZHR 159 (1995), 135, 159; Fuchs, WpHG, 2009, Einl. Rdn. 18.

17 SteinmeYer, in: Steinmeyer/Häger, WpÜG, 2. Aufl., 2007, \$35 Rdn. 102.

18 Vgl. $\$ 31$ WpÜG i. V.m. $\$ \$ 3$ ff WpÜG-AngV. 
siert insofern das Gleichbehandlungsgebot des $₫ 3$ Abs. $1 \mathrm{WpÜG}^{19}$ und dient der Anlegergleichbehandlung und dem Funktionenschutz. ${ }^{20}$

Ex post sollen zudem Schadensersatzpflichten die Gleichbehandlung der Anleger gewährleisten. Werden Ad-hoc-Informationen nicht unverzüglich veröffentlicht oder sind sie unwahr, stehen Anlegern individuelle Schadenersatzansprüche zu, $\mathbb{\int} \int 37 \mathrm{~b}, 37 \mathrm{c}$ WpHG. Hierdurch werden Verstöße gegen die informationelle Chancengleichheit aller Marktteilnehmer sanktioniert. ${ }^{21}$ Während für Verstöße gegen die Ad-hoc-Publizität Ansprüche aus $\$ 823$ Abs. 2 BGB ausdrücklich ausgeschlossen werden ( $\mathbb{1 5}$ Abs.6 Satz 1 WpHG), ${ }^{22}$ ist die Schutzgesetzeigenschaft für die übrigen marktbezogenen Informationspflichten jeweils einzeln zu ermitteln. ${ }^{23}$ Bejaht man die Schutzgesetzeigenschaft, fordert die Rechtsprechung zusätzlich, dass die Schaffung eines individuellen Schadensersatzanspruchs sinnvoll und im Lichte des haftungsrechtlichen Gesamtsystems tragbar erscheint. ${ }^{24}$ Schließlich handelt es sich um eine Grundsatzentscheidung des Gesetzgebers, außerhalb des $₫ 826$ BGB keinen allgemeinen Vermögensschutz zu gewähren. ${ }^{25}$

\section{c. Qualitätskontrolle der Informationen}

Wo notwendig, hat der Gesetzgeber Kontrollmechanismen vorgesehen, um im Sinne einer „Qualitätskontrolle“ die Richtigkeit und Vollständigkeit der Informationen zu überprüfen. Hier lässt sich von einer gestaffelten Qualitätskontrolle sprechen, findet diese doch inzwischen auf drei ganz unterschiedlichen Ebenen statt:

\section{aa) Compliance-Pflichten der Emittenten}

Unternehmensintern sind Emittenten und deren Dienstleister verpflichtet,

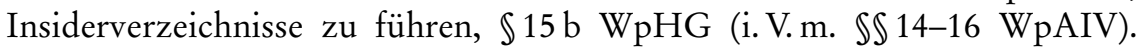
Dies verbessert die unternehmensinterne Prävention (Compliance) gegen In-

19 Schwennicke, in: Geibel/Süßmann, WpÜG, 2. Aufl., 2008, 33 Rdn. 3.

20 Steinmeyer, aaO (Fn. 17), $₫ 35$ WpÜG Rdn. 7; Meyer, in: Geibel/Süßmann, WpüG, 2. Aufl., 2008, $\$ 35$ Rdn. 8 m. w. N.

21 Sethe, in: Assmann/Schneider, WpHG, 6. Aufl., 2012, $\int \$ 37$ b, 37 c Rdn. 4.

22 S. Versteegen, Kölner Komm. z. WpHG, 2007, \$15 Rdn. 268 m. w. N.

23 Норт, ZHR 159 (1995), 135, 160; K. Sснмidt, FS Schwark, 2009, S. 753, 757 ff; SPINDLER, in: Langenbucher/Bliesener/Spindler, Bankrechts-Kommentar, 2013, $\$ 33$ Rdn. 12.

24 Grundlegend BGH, Urt. v. 8. 6.1976, BGHZ 66, 388, 390; Urt. v. 13. 4. 1994, BGHZ 125, 366, 374. Hierzu Spindler, aaO (Fn. 23), $\$ 33$ Rdn. 12, 64 f; Wagner, Münchener Komm. z. BGB, 5. Aufl., 2009, \823 Rdn. 329 f m.w.N.; SCHÄFER, WM 2007, 1872, 1873.

25 Spindler, aaO (Fn. 23), $₫ 33$ Rdn. 12; ebenso Assmann, FS Schneider, 2011, S. 37, 48 f. Im Einzelnen str. s. KRISL, Die Schutzgesetzeigenschaft der Wohlverhaltenspflichten nach den $\$ \mathbb{S} 31 \mathrm{ff} \mathrm{WpHG}, 2013$ (Diss. Augsburg). 
siderrechtsverstöße. ${ }^{26}$ Mit der Übermittlung von Insiderverzeichnissen an die BaFin $(\$ 15$ b Abs. 1 Satz 2 WpHG) und den Meldepflichten der Kredit- und Finanzdienstleister über börsliche und außerbörsliche Geschäfte ( $\$ 9 \mathrm{WpHG}$ ) wird zudem die Überwachung des Insiderhandelsverbots ( $\$ 14 \mathrm{WpHG})$ erleichtert. ${ }^{27}$ Werden infolgedessen Insidergeschäfte aufgedeckt, stellt sich zwangsläufig die Folgefrage, ob denn der Emittent seiner Ad-hoc-Publizitätspflicht aus $\$ 15 \mathrm{WpHG}$ nachgekommen ist. Ohne diese Verpflichtung Privater $^{28}$ ließen sich insiderrechtliche Verstöße nicht wirkungsvoll aufdecken.

\section{bb) Prüfungspflichten der Aufsichtsbehörde oder unabhängiger Dritter}

Auf einer zweiten Ebene sind bestimmte Informationen vor ihrer Veröffentlichung (ex ante) zu überprüfen, entweder aufsichtsrechtlich durch die BaFin oder durch der öffentlich-rechtlichen Aufsicht unterliegende private Dritte. Die Prüfung („Billigung“) der BaFin vor Prospektveröffentlichung beschränkt sich etwa allein darauf, ob der Prospekt vollständig ist, ob die Prospektangaben kohärent sind, also ohne innere Widersprüche, und ob der Prospekt verständlich ist, $\mathbb{1 3}$ Abs. 1 Satz 2 WpPG. Die Kohärenzprüfung beinhaltet zwar, dass die BaFin festgestellte Widersprüche dem Antragsteller mitteilen und Abhilfe anordnen muss, es handelt sich jedoch nicht um eine materielle Inhaltskontrolle, da der BaFin keine weiteren Unterlagen als der Prospekt vorzulegen sind. ${ }^{29}$

Die BaFin hat auch die (Pflicht-)Angebotsunterlage vor deren Veröffentlichung zu prüfen, $\mathbb{S} 15 \mathrm{WpÜG} .{ }^{30} \mathrm{Im}$ Gegensatz zum Prospekt hat die BaFin neben der Vollständigkeit und Vollzähligkeit der erforderlichen Angaben $(\$ 11$ Abs. 2 WpÜG, $\mathbb{\int} 2$ ff WpÜG-AngV) diese auch insoweit inhaltlich zu überprüfen, soweit Verstöße gegen das WpÜG oder die WpÜG-AngV „offensichtlich“ sind, $\$ 15$ Abs. 1 Nr. 2 WpÜG. ${ }^{31}$

Dagegen überprüft die BaFin keine Ad-hoc-Informationen . Sie sind der BaFin zwar vor Veröffentlichung mitzuteilen, $\mathbb{\$} 15$ Abs. 4 Satz 1 Nr. 3 WpHG. Damit soll der BaFin aber nur die Überwachung der Ad-Hoc-Publizitäts-

26 Sethe, aaO (Fn. 21), \15b WpHG Rdn.2 f; Heinrich, Kölner Komm. z. WpHG, 2007, $\$ 15$ b WpHG Rdn. 4.

27 S. Begr. RegE z. AnSVG v. 24. 5. 2004, BT-Drs. 15/3174, S. 36. Hierzu HeInRich, aaO (Fn. 26), $₫ 15$ b WpHG Rdn. 3 .

28 Heinrich, aaO (Fn. 26), $\$ 15$ b WpHG Rdn. 5.

29 Gross, Kapitalmarktrecht, 5. Aufl., 2012, $\$ 13$ WpPG Rdn. 8; ebenso v. КорP-Сolomb, in: WpPG/VerkProspG, 2. Aufl., 2010, $\$ 13$ WpPG Rdn. 9 ff; a. A. Berrar, Frankfurter Komm. z. WpPG/EU-ProspektVO, 2011, $\$ 13$ WpPG Rdn. 13.

30 Für $₫ 35$ WpÜG MeYer, aaO (Fn. 20), $₫ 35$ WpÜG Rdn. 66.

31 GeIbel, in: Geibel/Süßmann, WpÜG, 2. Aufl., 2008, \5 Rdn. 31. 
pflicht ex post ermöglicht werden. ${ }^{32}$ Weitere Vorabmitteilungen sind an die Geschäftsführungen inländischer Börsen zu richten ( $\mathbb{1 5}$ Abs. 4 Satz 1 Nr.3 WpHG). Die Börse prüft dann nicht die inhaltliche Richtigkeit, sondern ihr soll vor dem öffentlichen Bekanntwerden der Information nur die Möglichkeit eröffnet werden, im Zweifel den Kurs des Wertpapiers auszusetzen, $\mathbb{} 25$ Abs. 1 Nr. 1 BörsG. ${ }^{33}$ Selbst wenn man mit der BaFin eine Vorabmitteilung mindestens 30 Minuten vor Veröffentlichung der Ad-hoc-Mitteilung fordert, ${ }^{34}$ ist nicht mehr als eine Schlüssigkeitskontrolle zu erwarten. ${ }^{35}$

Für die Jahres- und Halbjahresberichte ist dagegen eine materielle Inhaltskontrolle durch der öffentlich-rechtlichen Aufsicht unterliegende Wirtschaftsprüfer vorgesehen, $\$ 37 \mathrm{w}$ Abs. $5 \mathrm{WpHG}$, $\mathbb{\$} 316,317 \mathrm{HGB}^{36}$

\section{cc) Kontrolle durch den Kapitalmarkt}

Im Übrigen findet quasi auf dritter Ebene eine ex post-Kontrolle der veröffentlichten Unternehmensinformationen dadurch statt, dass eine Vielzahl von Kapitalmarktinformationen zu veröffentlichen ist. Werden prognostizierte Geschäftszahlen nicht eingehalten und dies publik, ist in der Folge oftmals ein Kursverfall zu beobachten. Die Marktpreisbildung am Kapitalmarkt ist grundsätzlich ein effizienter Sanktionsmechanismus, da dem Management im worst case die Abberufung droht. ${ }^{37}$

\section{d) Verbote und andere Sanktionsmechanismen}

Über die gesetzlichen Pflichten zur Qualitätskontrolle hinausgehende Sanktionsmechanismen sind nur für Fehlverhalten erforderlich, das durch die

32 Begr. RegE z. 2. FFG v. 27. 1. 1994, BT-Drucks. 12/6679, S. 49; Bericht Finanzausschuss z. 2. FFG v. 15.6.1994, BT-Drs. 12/7918, S. 101. S. Zimmer/Kruse, in: Schwark/Zimmer, KMRK, 4. Aufl., 2010, $\$ 15$ WpHG Rdn. 95.

33 Vgl. BAFIn, Emittentenleitfaden 2009, S.73, abrufbar unter www.kapitalmarktrechtim-internet.eu. S. auch ZIMmeR/Kruse, aaO (Fn. 32), \$15 WpHG Rdn. 95.

34 BAFIN, Emittentenleitfaden 2009, S. 73, abrufbar unter www.kapitalmarktrecht-im-internet.eu; ebenso Assmann, in: Assmann/Schneider, WpHG, 6. Aufl., 2012, $\$ 15$ Rdn. 273. Im Gesetz finden sich hierfür keine Anhaltspunkte, kritisch daher VERSTEE-

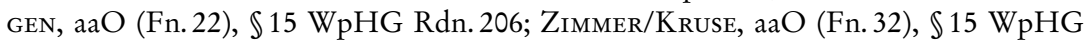
Rdn. 97.

35 Schließlich sollen sich die Börsen in diesem ohnehin kurzen Zeitraum auch noch mit anderen betroffenen Börsen koordinieren, s. BAFIN, Emittentenleitfaden 2009, S. 73, abrufbar unter www.kapitalmarktrecht-im-internet.eu.

36 Zum Umfang der Prüfungspflicht bspw. Eвke, Münchener Komm. z. HGB, 3. Aufl., 2013, $\$ 317$ Rdn. 43 ff.

37 Hierzu EkKenga/Schulz, in: Ehricke/Ekkenga/Oechsler, WpÜG, 2003, Einf. Rdn. $29 \mathrm{ff} \mathrm{m.} \mathrm{w.} \mathrm{N.}$ 
Marktpreisbildung nicht ausreichend sanktioniert wird. Dies ist beispielsweise bei einer unterlassenen Ad-hoc-Publizitätsmeldung über eine positive Nachricht der Fall. Unterlässt etwa der Emittent die Veröffentlichung einer strategischen Unternehmensentscheidung und hat die Maßnahme Erfolg, wird vielfach ein Kursanstieg zu beobachten sein. Die Marktpreisbildung als Sanktionsmechanismus der zuvor unterlassenen Veröffentlichung versagt in diesem Fall. Aus diesem Grund hat der Gesetzgeber für das Insiderrecht und Eingriffe in die Marktpreisbildung zu schärferen Schwertern gegriffen: Das Insiderhandelsverbot des $\ 14 \mathrm{WpHG}$ als „Kernstück“ der insiderrechtlichen Vorschriften $^{38}$ und die Vorschrift über Marktmanipulationen nach $\$ 20$ a WpHG sind als ausdrückliche Verbotstatbestände ausgestaltet. Flankiert werden sie durch Straftatbestände ( $\$ 38 \mathrm{WpHG}), \mathbb{1 5} \mathrm{WpHG}$ zusätzlich durch Schadensersatzpflichten ${ }^{39}$. Demgegenüber verzichtet das WpHG bei Verstößen gegen die Regelpublizität auf Sanktionen jenseits von Bußgeldern. Dies erscheint in Anbetracht der umfangreichen inhaltlichen Überprüfung vor Veröffentlichung auch sachgemäß. Somit gilt: Je umfangreicher die ex ante Qualitätskontrolle ausfällt, desto geringer ist das Bedürfnis für zusätzliche Sanktionsmechanismen.

\section{e) Zum Umgang mit Interessenkonflikten}

Interessenkonflikte spielen nur eine untergeordnete Rolle und sind vor allem dort zu beobachten, wo das Interesse der Marktteilnehmer an vollständiger und richtiger Unterrichtung mit den wirtschaftlichen Eigeninteressen des Emittenten kollidiert: $\mathbb{1} 15$ Abs. 2 Satz 1 WpHG statuiert das Verbot überflüssiger Veröffentlichungen. Hierunter fällt beispielsweise ein Missbrauch der Ad-hoc-Meldung zu Werbezwecken. ${ }^{40}$ Unzulässig ist auch die Verwendung im Geschäftsverkehr unüblicher Geschäftszahlen ( $\$ 15$ Abs.1 Satz 6 WpHG), beispielsweise dadurch, dass zum angeblichen Nachweis unternehmerischer Erfolge Phantasiekennzahlen verwendet oder durch den Wechsel der bisherigen Kennzahlen negative Entwicklungen verschleiert werden. ${ }^{41}$

Letztendlich kann ein Unternehmen aber nur zu positive oder unrichtige Informationen veröffentlichen - u. a. sanktioniert durch die Marktpreisbildung - oder eine geschuldete Information wird unterlassen. Hierfür hält das

38 So Assmann, aaO (Fn. 34), \14 WpHG Rdn. 1; Möllers/Ganten, ZGR 1998, 773, 774.

39 Gem. $\int \$ 37$ b, $37 \mathrm{c} \mathrm{WpHG}$, s. oben II.2.b).

40 Versteegen, aaO (Fn. 22), $\$ 15$ WpHG Rdn. 256.

41 Begr. RegE z. 4. FFG v. 14.11.2001, BR-Drucks. 936/01 (neu), S. 243. Hierzu auch Assmann, aaO (Fn. 34), $\$ 15$ WpHG Rdn. 193. 
Insiderrecht scharfe Sanktionen bereit. ${ }^{42}$ Notwendig ist die Aufdeckung etwaiger Eigeninteressen des Unternehmensmanagements durch $\$ 15$ a WpHG, anderenfalls wären diese Geschäfte der Marktpreiskontrolle entzogen. ${ }^{43}$

\section{Bewertung}

\section{a) Homo oeconomicus versus schutzbedürftiger Kleinanleger}

Wirtschaftstheoretische Grundlage der Informationspflichten ist die rational choice theory ${ }^{44}$ mit dem Leitbild des Homo oeconomicus, also einem Anleger, der alle bereitgestellten Informationen vollumfänglich aufnimmt, verarbeitet und auf dieser Grundlage rationale Anlageentscheidungen trifft. ${ }^{45}$ Eben diesen Homo oeconomicus scheint bisweilen auch der Kapitalmarktgesetzgeber als Anlegerleitbild vor Augen zu haben. ${ }^{46}$ Zunächst ist festzuhalten, dass der Homo oeconomicus aufgrund der eigenständigen Aufgabenzuweisung in den Wirtschaftswissenschaften kein subsumtionsfähiges Handlungskonzept darstellt. ${ }^{47}$ Subsumtionsfähig ist allein der „verständige Anleger“ als auslegungsbedürftiges Tatbestandsmerkmal der Insiderinformation, wie $\$ 13$ Abs. 1 Satz 2 WpHG verdeutlicht. Die h. M. begreift diese Rechtsfigur als börsenkundigen, also mit den Gegebenheiten des Kapitalmarkts vertrauten Anleger, ${ }^{48}$ der über alle im Markt bekannten Informationen verfügt. ${ }^{49}$ Aus-

42 S. oben II.2.d).

43 Wenngleich sich nicht zwangsläufig aus der Investitions- oder Desinvestitionsentscheidung des Managements Rückschlüsse auf Eigeninteressen herleiten lassen, vgl. HeINRICH, aaO (Fn. 26), $\$ 15$ a WpHG Rdn. 3.

44 Hierzu Jасову, 6 Roger Williams U. L. Rev. 81, 83 ff (2000-2001); Rubin, 80 Chi.-Kent. L. Rev. 1091, $1092 \mathrm{ff}$ (2005).

45 S. Griffith/Goldfarb, in: Koford/Miller, Social Norms and Economic Institutions, 1991, S.39, 44 ff; Kirchner, Ökonomische Theorie des Rechts, 1997, S. 11 ff; Kunz, Rational Choice, 2004, S. 32 ff; Kirchgässner, Homo Oeconomicus, 2. Aufl., 2000, S. $12 \mathrm{ff}, 46 \mathrm{ff}$.

46 CESR, CESR's Advice on Level 2 Implementing Measures for the proposed Market Abuse Directive, Dezember 2002, CESR/02-089 d, S. 10: „A piece of information is likely to have a significant effect $[\ldots]$ when $[\ldots]$ a reasonable investor $[\ldots]$ would be likely to take into account for his investment decision.“ sowie Fn. 1: „A reasonable investor is a person that thinks and behaves in a rational way." Zustimmend VeIL, ZBB 2006, 162, 163 m. Fn. 18; DERs., ZHR 172 (2008), 239, 249; KLÖHN, ZHR 177 (2013), 349, 367 ff, 376 f. Den Gesetzgeber kritisierend Möllers, FS Hopt, Bd. II, 2010, S. 2247, 2264.

47 Zutreffend Schwark/Kruse, in: Schwark/Zimmer, KMRK, 4. Aufl., 2010, 113 WpHG Rdn. 48; s. auch FLEISCHER, ZGR 2007, 500, 501.

48 S. Assmann, aaO (Fn. 34), $\$ 13$ WpHG Rdn. 58 mit zahlreichen w.N.

49 BAFIn, Emittentenleitfaden 2009, S. 33, abrufbar unter www.kapitalmarktrecht-im-internet.eu; s. auch Pawlik, Kölner Komm. z. WpHG, 2007, \$13 WpHG Rdn. 93; FLEI- 
legungsbedürftig ist auch das Anlegerleitbild, wenn es darum geht, nach wessen Kenntnisstand sich die Richtigkeit und Vollständigkeit des Wertpapierprospekts beurteilt. ${ }^{50}$ Der BGH stellt auf einen „durchschnittlichen“ Anleger ab, der zwar eine Bilanz lesen kann, aber nicht unbedingt mit der in eingeweihten Kreisen gebräuchlichen Schlüsselsprache vertraut zu sein braucht. ${ }^{51}$ Andere ziehen auch hier den „verständigen“ Anleger als Maßstab heran. ${ }^{52}$ Zwischenzeitlich scheint der Gesetzgeber jedoch erkannt zu haben, dass dieser verständige Anleger, anders als etwa der Homo oeconomicus, auf einfach verständliche Informationen angewiesen ist. So werden Vorgaben für die äußere Gestaltung von Ad-Hoc-Informationen aufgestellt (deutlich hervorgehobene Überschrift, Schlagwörter, $₫ 4$ Abs. 1 Satz 1 Nr.1 WpAIV). Insbesondere ist die Mitteilung kurz zu fassen ( $\$ 4$ Abs. 1 Satz 2 WpAIV), nach Vorstellung der BaFin möglichst nicht mehr als 10 bis 20 Zeichen. ${ }^{53}$ Des Weiteren müssen die Emittenten eine Prospektzusammenfassung ( $\$ 5$ Abs. 2 WpPG) zur Verfügung zu stellen. Durch die delegierte Verordnung zur Prospekt-RiL wurde hierfür ein einheitliches, leicht verständliches Format vorgegeben. ${ }^{54}$ Auch die Angebotsunterlage ist in einer Form abzufassen ist, „die ihr Verständnis und ihre Auswertung erleichtert“, $\mathbb{} 11$ Abs. 1 Satz 4 WpÜG.

\section{b) Das Anlegerleitbild: „Homo oeconomicus light“}

Die Konzeption der marktbezogenen Informationspflichten ist nicht auf den Schutz von Kleinanlegern ausgerichtet, deren fachliches Wissen und praktische Erfahrungen im Vergleich zu professionellen Anlegern oftmals deutlich zurückfallen. ${ }^{55}$ Vielmehr richten sich die Informationspflichten an die Anlegergesamt-

scher, NZG 2007, 4065; Harbarth, ZIP 2005, 1901 f; Lenenbach, aaO (Fn.8), Rdn. 13.126.

50 Zum vertretenen Meinungsspektrum m.w. N. Gross, aaO (Fn.29), \$21 WpPG Rdn. 68; Schwark, in: Schwark/Zimmer, KMRK, 4. Aufl., 2010, $\$ 45$ BörsG Rdn. 21 f. Für andere als Börsenprospekte indes BGH, Urt. v. 18. 9. 2012, WM 2012, 2147, 2150 : „... Fähigkeiten und Erkenntnismöglichkeiten eines druchschnittlichen (Klein-)Anlegers, der sich allein anhand der Prospektangaben über die Kapitalanlage informiert und über keinerlei Spezialkenntnisse verfügt.“ Hierzu MülbeRT, ZHR 177 (2013), 160, $178 \mathrm{f}$.

51 Vgl. BGH, Urt. v. 12.7.1982, NJW 1982, 2822, 2823.

52 Fleischer, Gutachten F z. 64. DJT, 2002, S. 44 ? f; zustimmend Gross, aaO (Fn. 29), $\$ 21$ WpPG Rdn. 41; Pankoke, in: Just/Voß/Ritz/Zeising, WpPG, 2009, \$S 44 BörsG, 13 VerkProspG Rdn. 39 mw.N.

53 Vgl. BAFIn, Emittentenleitfaden 2009, S. 70, abrufbar unter www.kapitalmarktrechtim-internet.eu.

54 S. Anhang XXII der Verordnung (EU) Nr. 486/2012 v. 30.3. 2012, ABl. EU Nr. L 101, S. 1 .

55 S. bereits Begr RegE z. 2. FFG, aaO (Fn. 32), S. 95; Beck, FS Schneider, 2011, S. 89, 94. 
heit und können schon deshalb nicht unterschiedliche Verständnishorizonte berücksichtigen. ${ }^{56}$ Auch für Kleinanleger gilt daher: Soweit sie die Anlageentscheidung allein auf Basis der verfügbaren marktbezogenen Informationen treffen wollen, setzt der Gesetzgeber voraus, dass alle Informationen vollumfänglich zur Kenntnis genommen und jedenfalls in den Grundzügen auch verstanden werden. Deutlich wird diese gesetzgeberische Entscheidung mit Blick auf das Prospektrecht: Nach der Vorstellung des Gesetzgebers ist die Prospektzusammenfassung lediglich als „Einführung“ zum Prospekt zu verstehen ( 55 Abs. 2 b Nr. 1 WpPG). Der Anleger ist ausdrücklich darauf hinzuweisen, dass er seiner Anlageentscheidung die Prüfung des gesamten Prospekts zugrunde zu legen hat ( $\$ 5$ Abs. 2 b Nr. 2 WpPG). Tut er dies nicht, ist eine Prospekthaftung allein aufgrund der Unrichtigkeit der Prospektzusammenfassung ausgeschlossen, ${ }^{57}$ \$ 23 Abs. 2 Nr. 5 WpPG. Kurz gefasst: Ohne Kenntnisnahme aller Informationen durch den Anleger auch keine Haftung des Emittenten. ${ }^{58}$ Dem Problem des information overload ${ }^{59} \mathrm{kann}$ dieses Informationsregime nur bedingt gerecht werden. Einfach verständliche Informationen reduzieren zwar die Komplexität, die Gefahr der Informationsüberlastung durch zu viele Informationen bleibt allerdings bestehen. Das gesetzgeberische Anlegerleitbild lässt sich insofern als „Homo oeconomicus light“ umschreiben - Regelungen zur besseren Verständlichkeit erleichtern zwar die Aufnahme komplexer Informationen, als conditio sine qua non gilt jedoch nach wie vor die Annahme, dass der Anleger die Informationsquantität vollumfänglich bewältigen kann.

Können oder wollen Anleger nicht alle verfügbaren Informationen vor der Anlageentscheidung aufnehmen und auswerten, müssen sie auf die (kostenpflichtigen) Dienste von Finanzintermediären vertrauen, die diese Aufgabe für sie übernehmen. ${ }^{60}$ Praktisch geht für Anleger in der Regel ohnehin kein Weg an Finanzintermediären vorbei, ${ }^{61}$ sie verfügen regelmäßig nur über einen mittelbaren Marktzugang. ${ }^{62}$ In der Folge spielen die marktbezogenen Informationen für Kleinanleger oft nur eine untergeordnete Rolle. ${ }^{63}$

56 So bereits Möllers/Kernchen, ZGR 2011, 1, 13, 16. S. Fleischer, Gutachten F z. 64. DJT, 2002, S. 21. Auch der EU-Gesetzgeber bezieht sich regelmäßig auf das Anlegerpublikum, Art. 8 Abs. 4 RiL 2001/34/EG v. 28.5.2001, ABl. EG Nr. L 184, S. 1.

57 Hierzu Gross, aaO (Fn. 29), \$23 WpPG Rdn. 11.

58 Vgl. auch BGH, Urt. v. 31.3.1992, NJW-RR 1992, 879, 881.

59 S. unten III.3.a).

60 Bereits Möllers/Kernchen, ZGR 2011, 1, 15 f. Für die Anlageberatung auch MüLBERT, ZHR 177 (2013), 160, 179.

61 So auch Begr. RegE z. 2. FFG v. 27.1.1994, BT-Drs. 12/6679, S. 97.

62 KüMPEL, Bank- und Kapitalmarktrecht, 3. Aufl., 2004, Rdn. 8.265, 8.267.

63 Zur Finanzberichterstattung ERnst/Gassen/Pellens, Verhalten und Präferenzen deutscher Aktionäre, Studien des Deutschen Aktieninstituts, 2009, S. 11, 29. Zum Geschäftsbericht in Großbritannien Bartlett/Chandler, 29 Brit. Account. Rev. 245 ff (1997) m. w. N. Zu Emissionsprospekten Rотн, in: Assmann/Schütze, Kapitalanlagerecht,

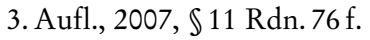




\section{Rationale Anlegerentscheidung durch Aufklärung}

\section{Regelungsziel}

Wo Informationsasymmetrien bestehen, durchbrechen Informationspflichten das Prinzip, dass grundsätzlich jedermann selbst dafür verantwortlich ist, sich vor Abschluss eines Geschäfts die notwendigen Informationen zu beschaffen. ${ }^{64}$ Mit dieser Systematik lässt sich auch $\$ 31 \mathrm{WpHG}$ begründen: ${ }^{65}$ Informationspflichten sollen den Anleger in die Lage versetzen, auf informierter Grundlage eine selbstbestimmte und eigenverantwortliche Anlageentscheidung zu treffen (vgl. $\$ 31$ Abs. 3 Satz $1 \mathrm{WpHG)}{ }^{66}$ Das Regelungsziel der informierten Anlegerentscheidung dient einerseits dem individuellem Anlegerschutz, schließlich setzen die $\$ \int 31 \mathrm{ff}$ WpHG eine konkrete Kundenbeziehung voraus. ${ }^{67}$ Die den Finanzintermediären durch $₫ 31 \mathrm{WpHG}$ auferlegte „Wissensvermittlung " lässt sich andererseits auch als Fortführung der Anlegergleichbehandlung ${ }^{68}$ und damit des institutionellen Anlegerschutzes ${ }^{69}$ verstehen: $\$ 31 \mathrm{WpHG}$ stellt die Informationsversorgung der Anleger sicher, sei es durch unmittelbare Informationspflichten gegenüber den Kunden, aber auch mittelbar dadurch, dass die Finanzintermediäre die am Markt verfügbaren Informationen aufnehmen, auswerten und an ihre Kunden weitergeben, beispielsweise in Form von Anlageempfehlungen. Jedenfalls der Theorie nach werden die Kunden der Finanzintermediäre durch dieses Informationsregime im Sinne eines „level playing field“ auf den Kenntnisstand der übrigen Marktteilnehmer versetzt. Neben den Informationen der Finanzintermediäre dient auch die bereits erwähnte Ad-hoc-Publizität der informierten Anlageentscheidung, ${ }^{70}$ was zuletzt vom BGH in seiner „IKB“-Entscheidung bestätigt wurde ${ }^{71}$.

64 Möllers/Leisch, JZ 2000, 1085; Fleischer, aaO (Fn. 10), 2001, S. 1003 f; Kahnert, Rechtsetzung im Europäischen Gesellschaftsrecht, 2012, S. 34 f.

65 Vgl. Begr RegE z. 2. FFG v. 27.1.1994, BT-Drs. 12/6679, S. 97.

66 Fuchs, aaO (Fn. 16), Vor $\int \mathbb{S} 31$ bis 37 a WpHG Rdn.53; Begr RegE z. 2. FFG v. 27.1.1994, BT-Drs. 12/6679, S. 103.

67 Ebenso Kasten, Die Neuregelung der Explorations- und Informationspflichten von Wertpapierdienstleistern im Wertpapierhandelsgesetz, 2009, S. 48, demzufolge der „individuelle Anlegerschutzkanon“ der MiFID I nicht auf allokative oder institutionelle Funktionen abstellt. MüLBERT, ZHR 177 (2013), 160, $172 \mathrm{f}$ begreift den individuellen Anlegerschutz dagegen „primär“ als Instrument des (allokativen) Funktionenschutzes.

68 S. oben II.1.

69 Begr RegE z. 2. FFG v. 27. 1. 1994, BT-Drs. 12/6679, S. 97; ebenso Fuchs, aaO (Fn. 16), Vor $\int \mathbb{S} 31$ bis 37 a WpHG Rdn. 52; Koller, in: Assmann/Schneider, WpHG, 4. Aufl., 2006, Vor $₫ 31 \mathrm{WpHG}$ Rdn. $9 \mathrm{ff}$.

70 S. bereits Möllers/Leisch, in: Langenbucher/Bliesener/Spindler, Bankrechts-Kommentar, 2013, $\$ 37$ b, c WpHG Rdn. 11.

71 BGH, Urt. v. 13. 12. 2011, BGHZ 192, 90 = NJW 2012, 1800, 1806 Rdn. 15, vorher schon ausführlich Möllers/Leisch, aaO (Fn. 70), \$37 b, c WpHG Rdn. 240-301. 


\section{Instrumente}

\section{a. Standardisierte Informationen}

Der Gesetzgeber verpflichtet die Wertpapierfirmen zur Kundenaufklärung mittels Standardinformationen ( $\$ 31$ Abs. 3 WpHG), Produktinformationsblättern ( $(31$ Abs.3 a WpHG), Warn- und Hinweispflichten ( $\$ 31$ Abs. 5 Satz 3 und 5, Abs. 7 Nr. 2 Satz 1 WpHG) sowie Angemessenheitsprüfungen ( $\$ 31$ Abs. 5 Satz 2 WpHG). Die Gemeinsamkeit dieser Informationspflichten liegt darin, dass sie - mit Ausnahme des Anlegerberichts ( $\$ 31$ Abs. 8 WpHG) - in standardisierter Form ${ }^{72}$ bzw. abstrakt erfüllt werden können.

\section{a) Standardinformationen}

Unabhängig von der jeweiligen Geschäftsart ${ }^{73}$ sind Privatkunden ( $\$ 31$ a Abs. 3 WpHG) die sogenannten Standardinformationen zur Verfügung zu stellen ( $\$ 31$ Abs. 3 WpHG). Diese sollen den Kunden konkret über das Wertpapierdienstleistungsunternehmen und dessen Dienstleistungen sowie abstrakt über Produktarten und vorgeschlagene Anlagestrategien einschließlich damit verbundener Risiken, Ausführungsplätze, Kosten und Nebenkosten informieren ( $\$ 31$ Abs. 3 Satz 4 WpHG). Die geplante MiFID II erweitert die Standardinformationen um folgende Angaben: Die der Empfehlung zugrunde liegende Produktpalette ${ }^{74}$, ob es sich um Produkte von Anbietern handelt, die zur Wertpapierfirma in enger Verbindung stehen, ${ }^{75}$ Angaben zur Beratungsgebühr und zu Provisionszahlungen und ob dem Kunden eine regelmäßige Beurteilung über die Eignung der Produkte erteilt wird. ${ }^{76}$ Zudem sind die voraussichtlichen Gesamtkosten der Anlage anhand einer Modellrechnung zu veranschaulichen. ${ }^{77}$

72 Die Standardisierung ist für die Basisinformationen gemäß $₫ 31$ Abs. 3 Satz 2 WpHG zulässig, für die Hinweise bei sonstigen und beratungsfreien Wertpapiergeschäften gemäß $₫ 31$ Abs. 5 Satz 5 und Abs. 7 Nr. 2 Satz 2 WpHG.

73 Die MiFID I nahm erstmals eine Systematisierung vor und unterscheidet „Anlageberatung und Portfoliomanagement“, „sonstige Wertpapiergeschäfte“ und „reine Ausführungsgeschäfte“, vgl. Art. 19 Abs. 3-6 MiFID I bzw. \31 Abs. 4-7 WpHG.

74 Nur bei Anlageberatung und Portfolioverwaltung.

75 Eine vergleichbare Informationspflicht statuiert bereits $₫ 5$ Abs. 2 Nr. 2 a WpDVerOV, s. Möllers/Wenninger, NJW 2011, 1697, 1699; Buck-Heeb, ZHR 177 (2013), 310, 317.

76 Art. 24 Abs. 3 Satz 1, 1. Spiegelstrich, Hs. 2, Abs. 3 a lit.a-d MiFID II-E (EUP), aaO (Fn. 4).

77 Art. 24 Abs. 3 Satz 2 MiFID II-E (EUP), aaO (Fn. 4). 


\section{bb) Produktinformationsblätter}

Der deutsche Gesetzgeber war in Europa Vorreiter, als er 2011 Wertpapierfirmen mit dem neu eingeführten $₫ 31$ Abs. 3 a WpHG ${ }^{78}$ dazu verpflichtete, ihren Kunden (ausschließlich) bei der Anlageberatung sogenannte Produktinformationsblätter zur Verfügung zu stellen. Zuvor hatte der europäische Gesetzgeber bereits OGAW-Fondsverwalter dazu verpflichtet, für Anleger in Quantität und Komplexität reduzierte, „wesentliche“ Anlegerinformationen (Key Investor Information Document, „KIID“) zu erstellen. ${ }^{79}$ Auch war vor Einführung der deutschen Produktinformationsblätter absehbar, dass der EU-Gesetzgeber die Übertragung des KIID-Konzepts auf alle PRIP (Packaged Retail Investment Products) ${ }^{80}$ und damit auch auf bestimmte Anlageprodukte im WpHGAnwendungsbereich ${ }^{81}$ plante. $^{82}$ Inzwischen finden sich vergleichbare Pflichten auch außerhalb des WpHG im VermAnlG und InvG. ${ }^{83}$ Grundsätzlich sollen die Produktinformationsblätter die wesentlichen Chancen und Risiken eines Anlageprodukts zusammenzufassen ${ }^{84}$ vergleichbar dem Beipackzettel für Arzneimittel ${ }^{85}$ oder den Produktinformationsblättern im Versicherungs- ${ }^{86}$ und im Verbraucherkreditrecht. ${ }^{87} \mathrm{Im}$ Juli 2012 stellte die Kommission ein Maßnahmenpaket vor, das u. a. den Vorschlag einer Verordnung über Basisinformationsblätter („VO-Basisinfo“) beinhaltete. ${ }^{88}$ Hiernach ist ein Basisinformati-

78 Eingefügt durch Art. 1 Nr. 6 AnsFuG v. 5. 4.2011, BGBl. I, S. 538. Hierzu Möllers/ WenNinger, NJW 2011, 1697, 1698.

79 Art. 78 RiL 2009/65/EG v. 13.7.2009, ABl. EU Nr. L 302, S. 32.

80 Unter dem Akronym PRIP werden (nicht-enumerativ) folgende Anlageprodukte zusammengefasst: Investmentfonds, Anlagen in Form von Lebensversicherungen, strukturierte Wertpapiere für Kleinanleger und strukturierte Termineinlagen, s. Kоммission, Mitteilung Anlageprodukte für Kleinanleger v. 30.4.2009, $\mathrm{KOM(2009)} 204$ endg., S. 3 f; zuletzt Vorschlag für eine Verordnung für Basisinformationsblätter für Anlageprodukte v. 3.7.2012, $\operatorname{KOM}(2012) 352$ endg. („VO-Basisinfo“).

81 Es handelt sich um solche PRIP, die zugleich unter den Begriff der Finanzinstrumente i.S.v. $\$ 2$ Abs. 2 b WpHG fallen, schließlich knüpfen hieran (bzw. über den Begriff der Wertpapier(neben)dienstleistungen, $\$ 2$ Abs. 3, Abs. 3 a WpHG) die für den Privatanle-

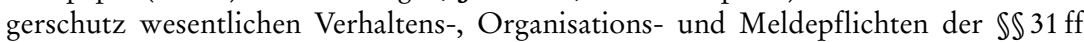
WpHG an.

82 Vgl. Kommission, Update on Commission Work on Packaged Retail Investment Products v. 16. 12.2009, S.3, abrufbar unter http://www.kapitalmarktrecht-im-internet.eu.

83 Vgl. \$13 VermAnlG (eingefügt durch Art. 1 VermAnlG v. 6. 12.2011, BGBl. I, S. 2481) und $₫ 42$ Abs. 2 InvG (eingefügt durch Art. 1 Nr. 36 OGAW-IV-UmsG v. 22.6. 2011, BGBl. I, S. 1126).

$84 \mathrm{Zu} \ 31$ Abs. 3 a WpHG Möllers/Wenninger, NJW 2011, $1697 \mathrm{f}$.

$85 \rrbracket 11$ AMG. Hierzu Nink/Schröder, PharmR 2006, 118.

86 Die gemäß $\$ 7$ Abs. 1 Satz 1 VVG i. V. m. $\ 1$ Abs. 1 VVG-InfoV erforderlichen Informationen sind in verkürztem Umfang in einem Produktinformationsblatt darzustellen, vgl. $₫ 4$ VVG-InfoV.

87 \491 a Abs. 1 BGB, Art. 247 \$2 EGBGB.

88 VO-Basisinfo, aaO (Fn. 80). S. Kommission, Pressemitteilung v. 3.7.2012, IP/12/736. 
onsblatt unabhängig von der jeweiligen Geschäftsart dem Kunden vor dem Erwerb eines Anlageproduktes zur Verfügung zu stellen. ${ }^{89}$ Verstöße gegen die Vorgaben (einheitliches Format, verständliche Sprache und Inhalt) ${ }^{90}$ sollen mit einem Schadensersatzanspruch des Kleinanlegers gegen den Produktanbieter sanktioniert werden. ${ }^{91}$ Kann der Anleger nachweisen, dass ihm infolge der Verwendung der „Beipackzettel“-Informationen ein Verlust entstanden ist, kommt ihm eine Beweislast zugute, weil der Anbieter nachweisen muss, dass das Informationsblatt den gesetzlichen Vorgaben entsprochen hat. ${ }^{92}$

\section{cc) Aufklärungs- und Warnhinweise}

Die MiFID I führte das beratungsfreie Geschäft („Execution only“, $\$ 31$ Abs. 7 WpHG) als neue Geschäftsart ein. ${ }^{93}$ Die Wertpapierfirma nimmt lediglich das vom Anleger gewünschte Geschäft vor, ohne dass eine Angemessenheits- oder Geeignetheitsprüfung stattfindet. Jenseits von Anlageberatung und Portfoliomanagement setzt der Gesetzgeber auf Anlegerschutz durch Warnhinweise: Bei beratungsfreien Geschäften ist zu warnen, dass keine Angemessenheitsprüfung durchgeführt wird ( $\$ 31$ Abs. 7 Nr. 2 Satz 1 WpHG), bei sonstigen Wertpapiergeschäften, wenn das Produkt nicht angemessen oder eine Angemessenheitsprüfung mangels Kundenangaben nicht durchführbar ist, $\$ 31$ Abs. 5 Satz 3 und 4 WpHG.

\section{b) Angemessenbeitsprüfung und Anlegerberichte}

Auf Aufklärung, nicht Beratung, zielt die Angemessenheitsprüfung bei den sonstigen Wertpapiergeschäften ab ( $\$ 31$ Abs. 5 Satz 2 WpHG), schließlich wird keine Empfehlung ausgesprochen. ${ }^{94}$ Anders als der Begriff suggeriert, bezieht sich die Prüfung zwar auf den konkreten Kunden, hinsichtlich des intendierten Wertpapiergeschäfts genügt jedoch eine abstrakte Betrachtung es geht weder um die wirtschaftliche Zweckmäßigkeit noch um die Angemes-

89 S. Art. 12 Nr. 1 VO-Basisinfo, (Fn. 80).

90 Art. 6-8 VO-Basisinfo, (Fn. 80).

91 Art. 11 Abs. 1 VO-Basisinfo, (Fn. 80).

92 Art. 11 Abs. 2, 3 VO-Basisinfo, (Fn. 80). Verstöße sollen zudem aufsichtsrechtlich sanktioniert werden, vgl. Artt. 18-21 VO-Basisinfo, (Fn. 80). Hierzu Gruber, ZFR 2012, 311, 313; Seitz/Juhnke/Seibold, BKR 2013, 1, $6 \mathrm{f}$.

93 S. Art. 19 Abs. 6 MiFID I, (Fn. 2). Bereits zuvor wurde vom BGH und zum Teil im Schrifttum vertreten, dass der Verzicht auf Beratungspflichten bei „execution only“-Geschäften prinzipiell zulässig sei: BGH, Urt. v. 5. 10.1999, NJW 2000, 359 (auf „gut informierte“ Anleger beschränkt); HoRn, ZBB 1997, 139, 151; LANG, Informationspflichten bei Wertpapierdienstleistungen, 2002, $\$ 17$ Rdn. 10 ff; a. A. Koller, in: Assmann/Schneider, WpHG, 2. Aufl., 1999, \31 Rdn. 127; Köndgen, ZBB 1996, 361, 365.

94 Lenenbach, aaO (Fn. 8), Rdn. 11.144. 
senheit der Konditionen des konkreten Geschäfts. ${ }^{95}$ Die Wertpapierfirma ist zudem dazu verpflichtet, jedem Anleger in „geeigneter Form“ unverzüglich über ausgeführte Geschäfte zu berichten ( $\$ 31$ Abs. 8 WpHG i.V.m. $\$ 8$ WpDVerOV). Diese Anlegerberichte sollen im Zuge der MiFID II deutlich erweitert werden. ${ }^{96}$

\section{c) Qualitätskontrolle durch interne Compliance}

\section{aa) Compliance-Pflichten der Wertpapierfirmen}

Auch für die Informationspflichten des $\$ 31 \mathrm{WpHG}$ ist eine zumindest doppelte Qualitätskontrolle vorgesehen: Bereits $₫ 33 \mathrm{WpHG}$ verpflichtet die Wertpapierfirmen dazu, organisatorische Maßnahmen zur Einhaltung der ge-

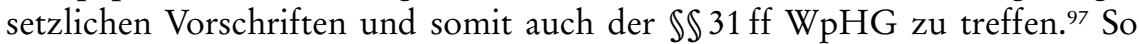
müssen „angemessene Grundsätze“ niedergelegt werden, die darauf ausgerichtet sind, dass die Wertpapierfirma selbst und ihre Mitarbeiter den Verpflichtungen des WpHG nachkommen ( $\$ 33$ Abs. 1 Satz 2 Nr. 1 WpHG). Die Aufgabe der einzurichtenden Compliance-Funktion ( $\mathbb{3} 3$ Abs. 1 Satz 2 Nr. 1 WpHG) beschränkt sich nicht darauf, ex post die Angemessenheit und Wirksamkeit der Grundsätze zu überwachen und regelmäßig zu bewerten $(\mathbb{S} 12$ Abs. 3 Nr. 1 WpDverOV). Vielmehr müssen die Mitarbeiter bereits ex ante bei der Erstellung der Grundsätze beraten und unterstützt werden ( $\mathbb{1} 12 \mathrm{Abs.} 2$ Nr. 2 WpDverOV). Die Compliance-Stelle wird letztlich dazu verpflichtet, die entsprechenden Regelwerke aufzustellen und in konkrete Handlungsanweisungen für das Tagesgeschäft umzusetzen. ${ }^{98}$ Was die Kundeninformationen des $₫ 31 \mathrm{WpHG}$ betrifft, muss die Compliance-Stelle daher die all-

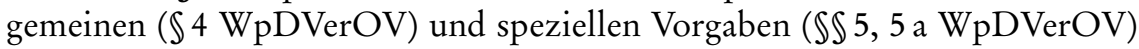
in geeigneter Form aufbereiten, beispielsweise indem verständliche und inhaltlich richtige Textbausteine zur Verfügung gestellt werden. ${ }^{99}$

95 Fuchs, aaO (Fn. 16), $\$ 31$ WpHG Rdn. 280.

96 Art. 25 Abs. 5 Satz 2 MiFID II-E, aaO (Fn. 3).

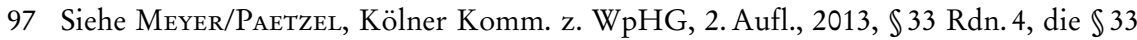

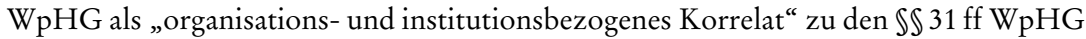
bezeichnen. $\$ 33 \mathrm{WpHG}$ wird durch die auf Grundlage von $₫ 33$ Abs. 4 WpHG erlassenen $\int \mathbb{S} 12,13 \mathrm{WpDVerOV}$ konkretisiert. Nicht um ein materielles Gesetz, sondern lediglich um interne Verwaltungsvorschriften handelt es sich bei BAFIN, Rundschreiben 4/2010 (WA) - Mindestanforderungen an die Compliance-Funktion und die weiteren

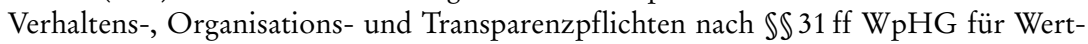
papierdienstleistungsunternehmen (MaComp), Stand 30.11.2012, abrufbar unter wrww.bafin.de.

98 So Meyer/Paetzel, aaO (Fn. 97), $\$ 33$ WpHG Rdn. 4.

99 Laut BaFin kann sich diese Überwachungspflicht unter bestimmten Voraussetzungen auch auf die von Dritten zur Verfügung gestellten Produktinformationen beziehen, s. BAFIn, MaComp, aaO (Fn. 97), BT 3.2.1.ff. 


\section{bb) Prüfungspflichten der Aufsicbtsbebörde und unabbängiger Dritter}

Dagegen ist eine Qualitätskontrolle der Kundeninformationen durch die BaFin vor deren Verwendung nicht vorgesehen. Ex post soll die Einhaltung der WpHG-Vorgaben durch das anlassunabhängige Sonderprüfungsrecht der BaFin $(\mathbb{S} 35$, 36 Abs. $4 \mathrm{WpHG}$ ) und die obligatorische Jahresprüfung $(\mathbb{S} 36$ WpHG) durch geeignete Prüfer ${ }^{100}$ sichergestellt werden. Eine Verpflichtung der BaFin de lege ferenda zur ex ante-Kontrolle der Kundeninformationen wäre im Übrigen als Überregulierung abzulehnen. Eine solche Aufgabe überstiege die ohnehin begrenzten Ressourcen der BaFin. Zudem beruhen Defizite des Anlegerschutzes de lege lata vor allem auf Interessenkonflikten ${ }^{101}$ und weniger auf unzureichenden Kundeninformationen.

\section{cc) Produktregulierung durch anbieterinterne Genehmigungsverfabren}

Im Zuge der MiFID II könnte erstmals die Entwicklung von Anlageprodukten der Qualitätskontrolle unterworfen werden: Nach Vorstellung des EUParlaments sollen die Wertpapierfirmen das Design von Finanzprodukten künftig so konzipieren, dass es den Bedürfnissen und Charakteristika eines bestimmten Zielmarkts innerhalb der anvisierten Kundenkategorie gerecht wird. ${ }^{102}$ Informationen über die beabsichtigte Zielgruppe sind Drittanbietern zur Verfügung zu stellen. ${ }^{103}$

Überdies sollen die Wertpapierfirmen selbst entwickelte Produkte vor Markteinführung einem anbieterinternen Genehmigungsverfahren unterziehen, das alle „wesentlichen Risiken“ überprüft. ${ }^{104}$ Die Produkte dürfen nur dann in Verkehr gebracht werden, wenn dies im Interesse der Kundenzielgruppe liegt. ${ }^{105}$ Die Übereinstimmung mit dem Kundeninteresse muss auch nach der Markteinführung regelmäßig überprüft werden, ebenso sind bereits im Vertrieb befindliche Produkte zu prüfen. ${ }^{106}$ Eine vergleichbare Regelung ist in den Niederlanden seit dem 1.1.2013 in Kraft: Wertpapierfirmen müssen sicherstellen, dass bei der Produktentwicklung die Interessen der von dem Produkt Begünstigten und der Produktkäufer gleichermaßen berücksichtigt

100 Wirtschaftsprüfer, vereidigte Buchprüfer sowie Wirtschaftsprüfungs- und Buchprüfungsgesellschaften. Hierzu Haussner, Kölner Komm. z. WpHG, 2007, \$36 WpHG Rdn. $19 \mathrm{ff}$.

101 Hierzu sogleich unten III.3.g), IV.3.b) und c).

102 Art. 24 Abs. 1 a Satz 1 MiFID II-E (EUP) (Fn. 4).

103 Art. 24 Abs. 1 a Satz 3 MiFID II-E (EUP) (Fn. 4).

104 Art. 16 Abs. 3 Satz 4-6 MiFID II-E (EUP) (Fn. 4).

105 Art. 16 Abs. 3 Satz 6 MiFID II-E (EUP) (Fn. 4).

106 Art. 16 Abs. 3 Satz 7 MiFID II-E (EUP) (Fn. 4). 
werden: so ist die relevante Zielgruppe des Anlageproduktes zu identifizieren und das Produktdesign hieran auszurichten. ${ }^{107}$

\section{d) Verbote}

\section{aa) Vertriebsbezogene Verbote für komplexe Finanzprodukte}

Um den Anleger vor riskanten Anlagen zu schützen, können über „Execution only“ nur "nicht-komplexe “108 Produkte erworben werden. ${ }^{109}$ Als "komplex“ eingestufte Derivate und Termingeschäfte ${ }^{110}$ sind dagegen nur mit Anlageberatung oder über den Weg der „sonstigen Wertpapiergeschäfte“ erhältlich. Nach Maßgabe der MiFID II ${ }^{111}$ soll der Kreis der komplexen Produkte künftig um Aktien von nicht-OGAW-konformen Investmentfonds, Schuldtitel und allgemein Geldmarktinstrumente mit einer Struktur erweitert werden, die es dem Kunden erschwert, die damit einhergehenden Risiken zu verstehen. ${ }^{112}$ Vergleichbares gilt für Aktien oder Anteile an sogenannten strukturierten OGAW. ${ }^{113}$ Auch soll der Anwendungsbereich von „Execution only“ auf Finanzinstrumente ausgedehnt werden, die von der Wertpapierfirma oder dem Kreditinstitut selbst emittiert werden. ${ }^{114}$

Das vom EU-Parlament vorgeschlagene anbieterinterne Genehmigungsverfahren soll durch ein Vertriebsverbot ergänzt werden: Anlageprodukte dürfen nur noch an Anleger der anvisierten Zielgruppe vertrieben wer-

107 S. Art. 32 Wijzigingsbesluit financiële markten 2013 v. 21.12.2012, abrufbar unter bttps://zoek.officielebekendmakingen.nl/stb-2012-695.html.

108 „Nicht komplex“ sind Aktien (die zum Handel an einem geregelten Markt oder an einem gleichwertigen Markt eines Drittlandes zugelassen sind), Geldmarktinstrumente, Schuldverschreibungen oder sonstige verbriefte Schuldtitel (sofern nicht in ein Derivat eingebettet) und Anteile an OGAW-Investmentfonds, vgl. Art. 19 Abs. 6, 1. Spiegelstrich MiFID I (Fn. 2); Art. 38 RiL 2006/73/EG v. 10. 8. 2006, ABl. EU Nr. L 241, S. 26 („MiFID I-DRiL“).

109 Art. 19 Abs. 6, 1. Spiegelstrich, S. 1 MiFID I (Fn. 2).

110 Art. 38 lit.a MiFID I-DRiL (Fn. 108) i.V.m. Art. 4 Abs. 1 Nr. 18 lit.c, Anhang I, Abschn. C Nr. 4-10 MiFID I (Fn. 2).

111 Vgl. Art. 25 Abs. 3 lit. a MiFID II-E (Fn. 3).

112 Art. 25 Abs. 3 lit. a (i)-(iii) MiFID II-E (EUP) (Fn. 4) sieht eine Ausnahme für Derivate vor, die das Risiko des Anlegers nicht erhöhen. Hierfür soll die ESMA Leitlinien aufstellen und regelmäßig aktualisieren, Art. 25 Abs. 7 MiFID II-E (Fn. 3).

113 Hierbei handelt es sich um OGAW, die für die Anleger zu bestimmten vorher festgelegten Terminen nach Algorithmen berechnete Erträge erwirtschaften, die an bestimmte Referenzwerte gebunden sind. S. Art. 25 Abs. 3 lit. a MiFID II-E (Fn. 3) i. V.m. Art. 36 Abs. 1 Unterabs. 2 VO (EU) Nr. 583/2010 v. 1.7.2010, ABl. EU Nr. L 176, S. 1.

114 Durch Ausweitung der Begriffsbestimmung „Ausführung von Kundenaufträgen“, vgl. Erwägungsgrund 30, Art. 4 Abs. 2 Nr. 4 MiFID II-E (Fn. 3). 
den. ${ }^{115}$ Verkaufsziele und interne Anreizsysteme sollen dem Verkauf oder dem Vertrieb des Anlageprodukts außerhalb der Zielgruppe keinen Vorschub leisten. ${ }^{16}$ Diese Vorgaben gelten für die Wertpapierfirma auch als Organisationsanforderungen. ${ }^{117}$

\section{bb) Produktverbote ex ante und ex post}

Zu den Aufgaben der ESMA zählt die Überwachung von Finanzprodukten und ggf. deren Verbot. ${ }^{118}$ Ebenso verfügen die nationalen Aufsichtsbehörden bereits nach geltendem Recht über Eingriffsbefugnisse nach Markteinführung. ${ }^{119}$ Die MiFID II-Vorschläge zur Produktregulierung sollen nach dem Willen des EUParlaments dahingehend ergänzt werden, dass die ESMA befugt ist den Produktvertrieb bereits vor Markteinführung (also ex ante) ${ }^{120} \mathrm{zu}$ beschränken und nötigenfalls ganz zu untersagen. ${ }^{121}$ Die Kompetenzen der nationalen Aufsichtsbehörden sollen entsprechend erweitert werden. ${ }^{122}$ In Großbritannien hat die neue Financial Conduct Authority (FCA) im Zuge des Financial Services Act $2012^{123}$ ähnliche ex ante-Interventionsrechte erhalten. ${ }^{124}$

115 Art. 24 Abs. 1 a Satz 2 MiFID II-E (EUP) (Fn. 4).

116 Art. 24 Abs. 1 a Satz 2 MiFID II-E (EUP) (Fn. 4).

117 Art. 16 Abs. 3 Satz 2 und 3 MiFID II-E (EUP) (Fn. 4).

118 Art. 9 Abs. 2, Abs. 5 VO (EU) Nr. 1095/2010 v. 24. 11. 2010, ABl. EU Nr. L 331, S. 84.

$119 \int \mathbb{\int} 4$ Abs. 2 Satz 2, 4 a Abs. 1 Satz 2 Nr. 1 WpHG. Nicht gegen ein einzelnes Produkt, sondern gegen einen den gesamten Kapitalmarkt betreffenden Missstand war das Verbot ungedeckter Leerverkäufe gerichtet, dass von der BaFin im Verlauf der Finanzmarktkrise ausgesprochen wurde. Hierzu CAHN/Müchler, BKR 2013, 45, 46.

120 Weder $₫ 4$ Abs. 2 Satz 2 WpHG noch $₫ 4$ a Abs. 1 Satz 2 Nr. 1 WpHG ermächtigen de lege lata zur präventiven Verhängung von Produktverboten: Für $\ 4$ Abs. 2 Satz 2 WpHG wird ein präventives Vorgehen nur in Bezug auf einzelne Personen oder ein einzelnes Unternehmen für zulässig gehalten, s. DöHmEL, in: Assmann/Schneider, WpHG, 6. Aufl., 2012, \4 Rdn. 25. \4 a Abs. 1 Satz 2 Nr. 1 WpHG ermächtigt zwar dazu, bereits vorbeugend den Handel mit einzelnen oder mehreren Finanzinstrumenten zu untersagen, sofern hierdurch Nachteile für die Stabilität der Finanzmärkte oder ein Vertrauensverlust bezüglich deren Funktionsfähigkeit verhindert werden. Allerdings lässt sich der Vorschrift nicht entnehmen, dass präventive Produktverbote bereits vor Markteinführung ausgesprochen werden dürfen.

121 Art. 31 Abs. 1, Abs. 2 Satz 2, Abs. 8 MiFIR-E (EUP) (Fn. 5). Zu den Voraussetzungen von ex ante-Maßnahmen Art. 31 Abs. 2 Satz 1 MiFIR-E (EUP) (Fn. 5). Vor einer Beschränkung oder einem Verbot ist zu warnen, dass ein Verbot oder eine Beschränkung droht, falls nicht bestimmte Änderungen an den Produktmerkmalen innerhalb einer festgesetzten Frist vorgenommen werden, Art. 31 Abs. 4 a MiFIR-E (EUP) (Fn. 5). Im Einzelnen CAHN/MÜCHLER, BKR 2013, 45, 47 ff.

122 Art. 32 Abs. 1, Abs. 2 Satz 2, Abs. 2 a, Abs. 6 MiFIR-E (EUP) (Fn. 5).

123 In Kraft getreten am 19.12.2012, vgl. bttp://www.legislation.gov.uk/ukpga/ 2012/21/enacted („Financial Services Act 2012“).

124 Vgl. Art. 137D Financial Services Act 2012 (Fn. 123) „The power of the FCA to make general rules includes power to make ... product intervention rules“. S. auch Financial 


\section{e) Zum Umgang mit Interessenkonflikten}

Wenn das der Aufklärung nachfolgende Wertpapiergeschäft als Eigenhandel ( 2 Abs. 3 Satz 1 Nr. 2 WpHG) durchgeführt wird, steht die Verpflichtung, im Kundeninteresse tätig zu werden, ${ }^{125}$ potentiell in einem Konflikt zu den wirtschaftlichen Eigeninteressen der Wertpapierfirma als Verkäufer. \$31 d WpHG konkretisiert die allgemeine Pflicht zur Vermeidung solcher Interessenskonflikte gemäß $₫ 31$ Abs. 1 Nr. 2 WpHG, indem Zuwendungen generell verboten werden. ${ }^{126}$ Zuwendungen ${ }^{127}$ sind ausnahmsweise zulässig, wenn sie die Wertpapier(neben)dienstleistung ermöglichen, für deren Erbringung notwendig sind ( $\$ 31 \mathrm{~d}$ Abs. $5 \mathrm{WpHG}$ ) oder die Zuwendung wird vom Kunden bzw. dem Kunden gewährt ( $\$ 31$ d Abs. 1 Satz 2 WpHG). Zuwendungen sind auch zulässig, wenn hierdurch die Qualität der Dienstleistung verbessert, die Interessenwahrungspflicht nicht beeinträchtigt und die Zuwendung offengelegt wird. ${ }^{128}$ Eine (aufsichts- bzw. zivilrechtliche) Aufklärungspflicht über Gewinnmargen beim Eigenhandel besteht hingegen nicht, Gewinnmargen sind - wie der BGH mit seiner umstrittenen „Lehman“-Rechtsprechung festgestellt hat ${ }^{129}$ - keine Zuwendungen. ${ }^{130}$

\section{Bewertung}

\section{a) Zum Problem des information overload}

Die vorgestellten Aufklärungspflichten werden dem Regelungsziel der rationalen Anlageentscheidung nicht gerecht. Der EU-Gesetzgeber hat offensicht-

Conduct Authority (FCA), Approach to Regulation, Juni 2011, Rdn. 5.26 und 5.30, abrufbar unter http://www.fsa.gov.uk/pubs/events/fca_approach.pdf.

125 Vgl. $\$ 31$ Abs. 1 Nr. 1 WpHG. Zum fiduziarischen Charakter der Geschäftsarten des \31 WpHG Möllers, Kölner Komm. z. WpHG, 2007, \31 Rdn. 7, 73 ff, 86. Zuvor bereits LeISCH, Informationspflichten nach $₫ 31 \mathrm{WpHG}, 2004$, S. 114.

126 \31 d Abs. 1 Satz 1 WpHG. S. Möllers, Kölner Komm. z. WpHG, 2. Aufl., 2013, \31 d Rdn.4; Koch, in: Schwark/Zimmer, KMRK, 4. Aufl., 2010, \31 d WpHG Rdn. 2; Koller, aaO (Fn. 7), \$31 d WpHG Rdn. 4; Herresthal, ZBB 2012, 89, 99.

127 Erfasst werden sowohl Provisionen, sonstige Gebühren und alle geldwerten Vorteile, \31 d Abs. 2 WpHG.

128 \31 d Abs. 1 Satz 1 Nrn. 1, 2 WpHG. Hierzu Koller, aaO (Fn. 7), $31 \mathrm{~d}$ WpHG Rdn. $27 \mathrm{ff}$.

129 BGH, Urt. v. 27. 9. 2011, NJW 2012, 66 (Leitsatz 5); Urt. v. 27. 9. 2011, NJW-RR 2012, 43, 47 Rdn. 47; bestätigt und erweitert auf Kommissionsgeschäfte durch Urt. v. 26.6.2012, NJW 2012, 2873 (Leitsätze). Zum Meinungsstand im Schrifttum vgl. die Nachweise des BGH, NJW 2012, 2873, 2876 Rdn. 33.

130 Möllers, Kölner Komm. z. WpHG, 2. Aufl., 2013, \31 d Rdn. 23; Koch, aaO (Fn. 126), $₫ 31 \mathrm{~d}$ WpHG Rdn.9, 19; Herresthal, ZBB 2012, 89, 99, m.w. N. in Fn. 125; BucK-HeEb, ZHR 177 (2013), 310, 332. 
lich das Problem der Informationsüberlastung in der Vergangenheit verkannt. Im Zusammenspiel mit den individuellen Aufnahme- und Verarbeitungskapazitäten des Empfängers definieren die Quantität und Komplexität von Informationen die Grenzen, innerhalb derer rationales Verhalten stattfinden kann (bounded rationality theory). ${ }^{131}$ Der Begriff information overload beschreibt den kognitiven Schwellenwert, bei dessen Überschreitung Informationen nicht mehr aufgenommen oder verarbeitet werden. ${ }^{132}$ Diese Erkenntnisse der Verhaltenspsychologie und Konsumentenforschung wurden zunächst für die Informationsmodelle im Vertrags ${ }^{133}$ und Verbraucherschutzrecht rezipiert. ${ }^{134}$ Inzwischen ist auch im Kapitalmarktrecht anerkannt, dass zu viele und zu komplexe Anlegerinformationen die Gefahr eines information overload begründen. ${ }^{135}$ In der Folge ist der Anleger nicht mehr in der Lage, rationale Anlageentscheidungen zu treffen und greift auf Vereinfachungsstrategien ${ }^{136}$ zurück.

\section{b) Standardisierte Informationserteilung}

Vor dem FRUG ${ }^{137}$ war umstritten, ob die Wertpapierfirmen ihre Informationspflicht ( $(31$ Abs. 2 Nr. 2 WpHG a.F.) durch abstrakte, standardisierte Informationen erfüllen können, oder ob in jedem Fall konkrete, individualisierte Informationen geschuldet sind. Die BaFin erklärte die standardisierte

131 Grundlegend Simon, 69 Q.J. E. 99 ff (1955); Miller, 63 Psych. Rev. $81 \mathrm{ff}$ (1956); Chase/Simon, 4 Cogn. Psych. 55, 76 (1973).

132 Jacoby/Speller/Kohn-Berning, 1 JcR 33 ff (1974); Malhotra, 8 JcR 419 ff (1982); DERS., 10 JcR $436 \mathrm{ff}$ (1984); BERNDT, Konsumentenentscheidung und Informationsüberlastung, 1983, S. 89; Hagemann, Wahrgenommene Informationsbelastung des Verbrauchers, 1988, S. 87.

133 Bspw. Fleischer, aaO (Fn. 10), S. 115; DERs., ZEuP 2000, 772, 798.

134 Drexl, Die wirtschaftliche Selbstbestimmung des Verbrauchers, 1998, S. 200; KIND, Die Grenzen des Verbraucherschutzes durch Information - aufgezeigt am Teilzeitwohnrechtegesetz, 1998; MarTineK, in: Grundmann, Systembildung und Systemlücken in Kerngebieten des Europäischen Privatrechts, 2000, S. 511, 522 ff; DERs., NJW 1997, 1393, 1396.

135 Möllers/Kernchen, ZGR 2011, 1 ff; Ders., JZ 2009, 861, 869; Ders./Holzner, NZG 2008, 166, 171 f; Versteegen, aaO (Fn. 22), \$15 WpHG Rdn. 16; Dreyling, Der Konzern 2005, 1, 5; SPindleR/SPeier, BB 2005, 2031, 2034. Im US-amerikanischen Schrifttum beispielsweise Prentice, 51 Duke L.J. 1397 ff (2002); Paredes, 81 Wash. U.L.Q. $417 \mathrm{ff}$ (2003).

136 Sog. Heuristiken. Hierunter werden Regeln oder Strategien der Informationswahrnehmung oder -verarbeitung verstanden, die dazu dienen, mit geringem Aufwand zu einem schnellen, aber nicht unbedingt optimalen Ergebnis zu kommen („Faustregeln“). Hierzu Möllers/Kernchen, ZGR 2011, 1, $10 \mathrm{ff} \mathrm{m.} \mathrm{w.} \mathrm{N.}$

137 Finanzmarktrichtlinie-Umsetzungsgesetz v. 16.7.2007, BGBl. I, S. 1330 („FRUG“). 
Informationserteilung für zulässig, ${ }^{138}$ die überwiegende Meinung im Schrifttum forderte hingegen generell ${ }^{139}$ konkret-individuelle Informationen. ${ }^{140}$ Nach der Umsetzung der MiFID I ${ }^{141}$ ist die standardisierte Informationserteilung dagegen zulässig. ${ }^{142}$ Nur noch bei der Anlageberatung ist konkretindividuell sowohl aufsichts- ( $\$ 31$ Abs. 4 WpHG) als auch zivilrechtlich (BGH-„,Bond“) ${ }^{143}$ aufzuklären. ${ }^{14}$ Durch standardisierte Prozesse lassen sich erhebliche Kostenersparnispotentiale realisieren, die Zulässigkeit standardisierter Informationserteilung liegt somit vor allem im Interesse der Wertpapierfirmen. Wenig verwunderlich dürfte sein, dass sich diese für das kostengünstigste Gestaltungsmodell „Maximalversorgung" entschieden haben: Implizit wird unterstellt, dass alle Anleger über unzureichende Finanzkenntnisse verfügen ${ }^{145}$ und daher unabhängig von ihrem individuellen Kenntnisstand mit „maximalen“ Informationen“ versorgt werden müssen. Der Umfang von z.Z. 168 Seiten $^{146}$ und die Komplexität der sogenannten Basisinformationen legen bei vielen Anlegern einen information overload nahe. ${ }^{147}$ Zwar gilt auch hier das Verständlichkeitsgebot, ${ }^{148}$ die Verständlichkeit bestimmt sich jedoch nach den Fähigkeiten des „Durchschnittsanlegers“. ${ }^{149}$ Damit wird bewusst in Kauf genommen, dass Anleger mit unterdurchschnittlichen Fähigkeiten schutzlos bleiben. ${ }^{150}$ Dabei wären diese in besonderem Maße schutzbedürftig, benötigen sie doch am dringendsten verständliche Informationen. ${ }^{151}$ Ohnehin dürften Verstöße gegen das Verständlichkeitsgebot sanktionslos bleiben: Um nachzuweisen, dass die Informationserteilung für

138 B.2.2. der Richtlinie zur Konkretisierung der $\$ \$ 31$ und 32 WpHG v. 23. 8. 2001, BAnz. Nr. 165 v. 4. 9.2001, S. 19217.

139 Unabhängig von der Geschäftsart, vgl. Koller, aaO (Fn. 69), \31 WpHG Rdn. 132.

140 Gegen die Zulässigkeit Koller, in: Schneider, WpHG, 3. Aufl., 2003, \31 Rdn. 96 a, 104; DERs., aaO (Fn. 69), $\$ 31$ WpHG Rdn. 132; LeIsCH, Informationspflichten nach \31 WpHG, 2004, S. 133 f; Möllers/Ganten, ZGR 1998, 773, 785 ff; a. A. Bliesener, Aufsichtsrechtliche Pflichten beim Wertpapierhandel, 1998, S. 297 ff.

141 Art. 19 Abs. 3 Satz 2 MiFID I (Fn. 2).

142 \$31 Abs. 3 Satz 2 WpHG und oben Fn. 72.

143 BGH, Urt. v. 6.7.1993, BGHZ 123, 126, $128 \mathrm{ff}$.

144 Fuchs, aaO (Fn. 16), $\$ 31$ WpHG Rdn. 242, 250.

145 Koller, aaO (Fn. 7), $\$ 31$ WpHG Rdn. 93 c. Die zu benennenden Risiken führt $\$ 5$ Abs. 1 Satz 2 WpDVerOV auf.

146 Vgl. Basisinformationen über Wertpapiere und weitere Kapitalanlagen, Bank-Verlag.

147 Zutreffend Koller, aaO (Fn. 7), \$31 WpHG Rdn. 93 c.

$148 \rrbracket 31$ Abs. 3 Satz 1 WpHG, $\mathbb{} 4$ Abs. 1 Satz 1 WpDVerOV.

149 Hierzu Koller, aaO (Fn. 7), $\$ 31$ WpHG Rdn. 93 c, 95, 62 ff. S. auch Bafin, MaComp (Fn. 97), BT 3.3.3.1.2.

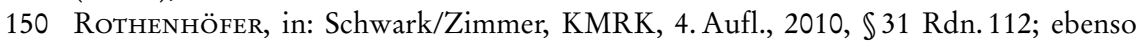
Koller, aaO (Fn. 7), \31 WpHG Rdn. 66; Buck-HeEb, ZHR 177 (2013), 310, 316.

151 Koller, aaO (Fn. 7), $\$ 31$ WpHG Rdn. 93 c und verweist zu den Defiziten an finanzieller Allgemeinbildung auf Habschick/Evers, Anforderungen an Finanzvermittler - mehr Qualität, bessere Entscheidungen, Studie im Auftrag des BMELV, 2008, S. 17, 125; LEUERING/ZETZSCHE, NJW 2009, 2856, 2861. 
den Durchschnittsanleger unverständlich ist, müsste zunächst der Durchschnittsanleger definiert werden, was praktisch kaum darstellbar ist. Der EUGesetzgeber scheint sich dieser Fehlkonzeption bewusst geworden zu sein: So sollen nach dem MiFID II-Entwurf wieder die Mitgliedsstaaten entscheiden können, ob sie eine Standardisierung wollen ${ }^{152}$; des Weiteren sollen die Basisinformationen durch die geplante Modellrechnung transparenter werden ${ }^{153}$. Beide Vorschläge sind mit Nachdruck zu begrüßen. Eine ähnliche Modellrechnung ist im Übrigen bereits für die Verbraucherkredit-Werbung vorgesehen: Nach $\$ 6$ a PAngV sind die Kreditkonditionen anhand eines repräsentativen Jahreszinses zu veranschaulichen.

\section{c) Produktinformationsblätter}

Anstatt mit $₫ 31$ Abs. 3 a WpHG auf nationaler Ebene vorzupreschen, hätte der deutsche Gesetzgeber die inzwischen konkret gewordene EU-Regelung abwarten sollen: So ist schon heute absehbar, dass die bestehenden WpHGInformationsblätter nicht den Vorgaben der VO-Basisinfo entsprechen. ${ }^{154} \mathrm{An}-$ ders als für das deutsche Produktinformationsblatt ist beispielsweise eine vereinheitlichte Darstellung vorgesehen. ${ }^{155}$ Weil so tatsächlich ein Vergleich verschiedener Produkte möglich wird, ist dieser Vorschlag zu begrüßen. ${ }^{156}$ Allerdings werden in der Folge kostenintensive Anpassungen nötig. Im Vergleich zum EU-Vorschlag wirken die WpHG-Regelungen zudem unausgegoren: Nach $₫ 31$ Abs. 3 a WpHG ist ein Informationsblatt nur für empfoblene Produkte zur Verfügung zu stellen. Da sich die Empfehlung aber regelmäßig auf ein einzelnes Produkt beschränken muss, ${ }^{157}$ stellt sich die von $\$ 31$ Abs. 3 a WpHG bezweckte verbesserte Vergleichbarkeit verschiedener Produkte ${ }^{158}$ nur dann ein, wenn sich der Kunde noch anderweitig beraten lässt und hierdurch weitere Informationsblätter erhält. ${ }^{159}$ In der Beratungspraxis ist dies ein eher unrealistisches Szenario.

Art. 12 Abs. 1 der geplanten VO-Basisinfo ${ }^{160}$ beschränkt dagegen die Pflicht zur Aushändigung des Informationsblatts nicht auf die Anlageberatung. Dies

152 Art. 24 Abs. 3 a Satz 3 MiFID II-E (EUP) (Fn. 4).

153 Art. 24 Abs. 3 Satz 2 und 3 MiFID II-E (EUP) (Fn. 4).

154 Hierzu Seitz/Juhnke/Seibold, BKR 2013, 1 ,4, 7.

155 Im Gegensatz zu $₫ 31$ Abs. 3 a WpHG i. V. m. $\ 5$ a WpDVerOV Vgl. zu den detaillierten Vorgaben an Form und Inhalt bereits oben III.2.a)bb).

156 Zur diesbezüglichen Kritik an $\$ 31$ Abs. 3 a WpHG Косн, BKR 2012, 485, 487 m.w. N.; a.A. Möllers/Wenninger, NJW 2011, 1697, 1698; Hartrott/Voigt, RdF 2012, 87, 91.

157 Koller, aaO (Fn. 7), $\$ 31$ WpHG Rdn. 132.

158 Begr RegE z. AnsFuG, aaO (Fn. 12), S. 21.

159 Koller, aaO (Fn. 7), $\$ 31$ WpHG Rdn. 122.

160 S. bereits Fn. 80. 
erscheint zweckmäßig, schließlich werden bei der Anlageberatung ohnehin konkrete Produktinformationen geschuldet. Sinnvoll ist des Weiteren, dass der EU-Vorschlag im Gegensatz zu $₫ 31$ Abs. 3 a WpHG Aktien und Anleihen von der Informationsblatt-Pflicht ausnimmt (vgl. Art. 2 lit. d VO-Basisinfo). Hierdurch wird einer Überregulierung vorgebeugt, schließlich bestehen bei nicht-strukturierten Wertpapieren geringere Verlustrisiken als z. B. bei Derivaten.

Dem deutschen Gesetzgeber ist zugute zu halten, dass er sich immerhin bemüht hat, mit den Produktinformationsblättern des $\$ 31$ Abs. 3 a WpHG dem information overload entgegenzuwirken. Das Ziel, die Informationseffizienz $\mathrm{zu}$ verbessern, wird indes konterkariert, wenn die Informationsblätter mit einer Flut anderer Informationen wie z. B. dem Produktprospekt überreicht werden (dürfen) und infolgedessen im Papierberg „untergehen“. ${ }^{161}$

Letztendlich können auch EU-Informationsblätter nicht darüber hinwegtäuschen, dass der informationsbasierte Anlegerschutz seine „systemimmanenten Grenzen" erreicht hat. ${ }^{162}$ Simplifizierende Informationsblätter mögen für einfach konstruierte Produkte wie Investmentfondsanteile einen gewissen Nutzen haben. ${ }^{163}$ Bei komplexen Produkten versagt das Regelungskonzept hingegen: Wenn sich deren Risiken noch nicht einmal in umfangreichen Beratungsgesprächen näher bringen lassen, wie etwa der Sachverhalt im Zinswette-Urteil verdeutlicht, ${ }^{164}$ ist erst recht keine aussagekräftige Zusammenfassung auf drei DIN-A4-Seiten ${ }^{165} \mathrm{zu}$ erwarten. ${ }^{166}$

\section{d) Anlegerberichte}

Die Anlegerberichte in der heutigen Form sind nicht besonders anschaulich. Zur Bestätigung über ausgeführte Geschäfte „in angemessener Form“ soll bereits die Angabe von Standardcodes genügen, soweit eine Erläuterung der verwendeten Codes beigefügt wird, $\$ 8$ Abs. 2 Satz $3 \mathrm{WpDVerOV.} \mathrm{Eine} \mathrm{nicht}$ nur transaktionsbezogene, sondern regelmäßige Berichtspflicht war bislang nur dann (alternativ) vorgesehen, wenn regelmäßig Aufträge von Privatkunden über Investmentanteile ausgeführt werden, $\mathbb{} 8$ Abs. $5 \mathrm{WpDVerOV}$. Im Zuge der MiFID II soll die Pflicht zur regelmäßigen Berichterstattung

161 Müller-Christmann, DB 2011, 749, 751. S. Кoch, BKR 2012, 485, 487.

162 S. КосH, BKR 2012, 485 ff; zuvor bereits KÖNDGEN, BKR 2012, 283 ff; DERs., FS Hopt, Bd. II, 2010, S. 2113, $2138 \mathrm{ff}$.

163 Hierzu Podewils, ZBB 2011, 169 ff; s. Köndgen, BKR 2012, 283, 285.

164 BGH, Urt. v. 22.3.2011, BGHZ 189, 13 - Zinswette. Siehe unten IV.2.b)bb), III.3.f).

165 Vgl. $₫ 5$ a Abs. 1 Satz 1, 2. Alt. WpDVerOV.

166 KöNDGEN, BKR 2012, 283, 285. Zur ähnlichen Kritik für wesentliche Anlageinformationen nach dem geplanten KAGB s. Möllers, NJW 2012, Heft 52 Editoral. 
auf alle Geschäfte mit Finanzinstrumenten ausgeweitet werden. ${ }^{167}$ Auch soll künftig die Art und Komplexität der Produkte angegeben werden. Diese Vorschläge bilden einen deutlichen Fortschritt, weil sich dadurch der Anleger auf einfache Weise einen Überblick über die Struktur und Kosten seiner Anlagen zu verschaffen kann. Zudem kann er so seine getätigte Entscheidungen ex post besser nachvollziehen.

\section{e) Anlegerschutz beim Vertrieb nicht-komplexer und komplexer Produkte}

\section{aa) Status quo: Unzureichender Anlegerschutz}

Der Anlegerschutz beim Vertrieb nicht-komplexer Produkte über den Vertriebskanal „Execution only“ richtet sich nach $\$ 31$ Abs. 7 WpHG. Für das Wertpapierunternehmen besteht weder die Pflicht zur Exploration noch zur Durchführung einer Geeignetheits- oder Angemessenheitsprüfung. ${ }^{168}$ Der Anlegerschutz ist bisher unzureichend, weil der Gesetzgeber allein auf den Anleger vermeintlich aufrüttelnde Warnhinweise setzt. Ein solcher Warnhinweis darf zwar nicht unverständlich oder abgeschwächt dargestellt werden. ${ }^{169}$ Gesetzlich ist jedoch kein Formerfordernis für die Erteilung vorgesehen, es besteht lediglich eine (schriftliche) Dokumentationspflicht. ${ }^{170}$ Die Warnhinweise dürfen überdies in standardisierter Form erteilt werden. ${ }^{171}$ Auch hier ist wiederum ein information overload zu befürchten. Noch gravierender ist allerdings, dass selbst diese rudimentären Warnhinweise entbehrlich sind, wenn der Anleger einen Vertriebskanal wählt, der ausschließlich für „Execution only" eröffnet ist, ${ }^{172}$ z. B. das beliebte Discount Broking. Zusammenfassend ist „Execution only“ daher als Vertriebskanal einzustufen, in dem das $\mathrm{Maß}$ an übertragener Eigenverantwortlichkeit regelmäßig die Fähigkeiten des durchschnittlichen Privatanlegers übersteigen dürfte.

Der Anlegerschutz ist freilich ebenso unzureichend, wenn Anleger komplexe Produkte ohne Anlageberatung erwerben möchten. Die nach $\$ 31$ Abs. 5 WpHG vorgesehenen Warnhinweise ${ }^{173}$ sind aus den bereits genannten Gründen nicht ausreichend. Zusätzlich ist zwar eine Angemessenheitsprüfung vorzunehmen. Diese beschränkt sich aber auf die Kundenangaben zur Geschäftserfahrenheit, $\$ 31$ Abs. 5 Satz 1 und 2 WpHG. Die Wertpapierfirma kann folglich nur abstrakt überprüfen, ob der Kunde die mit der Anlage einher-

167 Art. 25 Abs. 5 MiFID II-E (EUP) (Fn. 4).

168 Rothenhöfer, aaO (Fn. 150), $\$ 31$ WpHG Rdn. 318.

169 \31 Abs. 7 Nr. 2 WpHG i. V.m. \4 Abs. 2 Satz 2 WpDVerOV.

170 Koller, aaO (Fn. 7), $\$ 31$ WpHG Rdn. 192.

171 \31 Abs. 3 Satz 2 WpHG, s. Fn. 72.

172 Koller, aaO (Fn. 7), §31 WpHG Rdn. 192, der als Beispiel nur über Internet, Telefon oder Telefax erreichbare Discount-Broker nennt.

173 Oben III.2.a)cc). 
gehenden Risiken durchschauen kann. Jenseits des $₫ 31$ Abs. 6 WpHG findet somit nur eine Plausibilitätskontrolle statt, wobei die Wertpapierfirma selbst dann nicht zur Nachprüfung verpflichtet sein soll, wenn starke Indizien für die Fehlerhaftigkeit oder Unvollständigkeit der Kundenangaben sprechen. ${ }^{174}$ Zwar darf nicht zwangsläufig davon ausgegangen werden, dass der Kunde die zur Verfügung gestellten Standardinformationen tatsächlich zur Kenntnis genommen hat, ${ }^{175}$ die Wertpapierfirma bleibt also zur Erkundigung verpflichtet. Die Behavioral Finance-Forschung legt jedoch nahe, dass Anleger zur Selbstüberschätzung ihrer Kenntnisse und Erfahrungen neigen ${ }^{176}$ und diese in den meisten Fällen umfassender angeben werden als sie der Realität entsprechen. Eine rationale Anlegerentscheidung ist damit auch hier nicht gewährleistet.

\section{bb) Forderung nach einer Einführung eines Schriftformerfordernisses}

Nimmt der Anleger die Dienstleistung der Anlageberatung in Anspruch, muss er insbesondere vor eigennützigen Empfehlungen des Anlageberaters geschützt werden. Jenseits der Anlageberatung ist jedoch primär ein stärkerer Schutz des Anlegers vor sich selbst und unüberlegten Entscheidungen erforderlich. Diese Feststellungen gelten auch für die vom Gesetzgeber als „nichtkomplex" eingestuften Produkte. Diese können einerseits durchaus eine Komplexität aufweisen, die Fehlentscheidungen geradezu vorprogrammiert, andererseits findet bei „Execution only“, anders als bei sonstigen Geschäften, keinerlei Exploration statt. Die Notwendigkeit eines besseren Schutzes des Anlegers vor sich selbst unterstreicht nicht zuletzt der Vorschlag der MiFID II, den Kreis der „Execution only“-tauglichen Produkte weiter einzuschränken. ${ }^{177}$

Aus diesen Gründen ist die Einführung eines generellen Schriftformerfordernisses für Auftragserteilungen im Wege von „Execution only“ und „sonstiger Wertpapiergeschäfte" zu fordern. Selbstverständlich kann auch die Warnfunktion ${ }^{178}$ der Schriftform keinen absoluten Schutz vor Fehlentscheidungen bieten. Aller Voraussicht nach würde aber zumindest die Wahrscheinlichkeit unüberlegter Anlageentscheidungen reduziert. Damit ist auch die Streichung des Schriftformerfordernisses bei Finanztermingeschäften ( $\$ 37 \mathrm{~d}$ Abs. 1 Satz 2 WpHG a. F. $)^{179}$ zu kritisieren. ${ }^{180}$ Systematisch folgerichtig wäre die Einfüh-

174 Fuchs, aaO (Fn. 16), $₫ 31$ WpHG Rdn. 282.

175 Koller, aaO (Fn. 7), \31 WpHG Rdn. 177; Spindler/Kasten, WM 2007, 1797, 1800.

176 Hierzu bspw. KLÖHN, Kapitalmarkt, Spekulation und Behavioral Finance, 2006, S. $117 \mathrm{ff}$.

177 S. bereits oben III.2.d.

178 Zum Übereilungsschutz des $₫ 126$ BGB bspw. Einsele, Münchener Komm. z. BGB, 6. Aufl., 2012, \126 Rdn. 1.

179 Art. 1 Nr. 30 FRUG (Fn. 137).

180 S. bereits Möllers, FS Hopt, S. 2247, 2257. 
rung der Schriftform für Geschäfte i.S.d. $\$ \mathbb{S} 31$ Abs. 5 und 7 WpHG de lege ferenda ohnehin. Schließlich setzt der Gesetzgeber bereits de lege lata überall dort, wo ein reduzierter Anlegerschutz mit erhöhten Risiken einhergeht, auf eben dieses Instrument: Sowohl bei der Hochstufung vom Privatkunden zum professionellen Kunden ( $\$ 31$ Abs. 7 WpHG) als auch vom Privatanleger zum semi-professionellen Anleger ( $\$ 1$ Art. 19 Nr. 33 KAGB-E) ist über die Konsequenzen der Hochstufung schriftlich zu informieren ${ }^{181}$ und der Kunde/Anleger muss sein schriftliches Einverständnis erteilen. ${ }^{182}$

\section{f) Produktregulierung}

Die Vorschläge zur Produktregulierung setzen einen neuen Regelungsschwerpunkt des Anlegerschutzrechts. Das EU-Parlament hat im Zuge der MiFID II-Reform bereits sehr deutlich artikuliert, dass verschärfte Wohlverhaltenspflichten zwar notwendig seien, aber alleine nicht ausreichten, um einen angemessenen Anlegerschutz zu gewährleisten. ${ }^{183}$

Die Produktregulierung, insbesondere in der Form des Verbotes, greift zwar in die Vertragsfreiheit der Anleger ein, da die verfügbare Produktpalette eingeschränkt wird. Die Vertragsfreiheit kann aber nur bestehen, soweit der Anleger frei entscheiden kann. Wenn also der Vertrieb von Produkten beschränkt werden soll, deren Risiken aufgrund ihrer Komplexität weder mittels seitenlanger Erläuterungen noch durch ausführlichste Beratung vermittelt werden können, ${ }^{184}$ dann schränkt diese Produktregulierung nicht die Vertragsfreiheit ein, sondern stellt nur deren Grundvoraussetzung, nämlich Entscheidungsfreiheit, wieder her. Erfreulicherweise finden sich in der Praxis bereits Fälle, in denen Banken die verfügbaren Klassen auf nachvollziehbare Produkte reduzieren. ${ }^{185}$

Eine solche Produktregulierung wäre auch verhältnismäßig, weil sie keine generelle, staatliche Genehmigungspflicht ${ }^{186}$ vor Markteinführung darstellt,

181 \31 a Abs. 7 Satz 4 WpHG i. V.m. $\ 2$ Abs. 2 Satz 1 Nr. 2 WpDVerOV bzw. $\$ 1$ Abs. 19 Nr.33 lit. a) ee) KAGB-E.

182 \31 a Abs. 7 Satz 5 WpHG i. V.m. \$2 Abs. 2 Satz 1 Nr. 3, Abs. 2 Satz 2 WpDVerOV, sowie Koch, aaO (Fn. 126), $₫ 31$ a WpHG Rdn. 51 f bzw. $\$ 1$ Abs. 19 Nr. 33 lit. a) bb) KAGB-E.

183 Erwägungsgrund 51 a MiFID II-E (EUP) (Fn. 4).

184 Unten IV.2.b)bb).

185 Die ING DiBa als größte deutsche Direktbank reduzierte die für Privatanleger verfügbaren Anlageklassen auf die Hälfte und der CEO begründete dies damit: „Bankkunden sollen einfache Produkte kaufen“, FAZ v. 29.11.2012, S. 20.

186 Kommission, Update on Commission Work on Packaged Retail Investment Products v. 16.12.2009, S. 45, abrufbar unter http://www.kapitalmarktrecht-im-internet.eu: „full ex ante authorisation regime“. 
wie etwa der von der Kommission im Vorfeld der MiFID II-Vorschläge bereits abgelehnte „Finanz-TÜV““. ${ }^{187}$ Weder das anbieterinterne Genehmigungsverfahren noch die Befugnisse zur Produktintervention ex ante sind hiermit vergleichbar, weil den Behörden lediglich die Notfallkompetenz eingeräumt wird, gegen einzelne Produkte und nur unter engen Voraussetzungen vorgehen zu dürfen. ${ }^{188}$ Die zwar generelle, aber anbieterinterne Genehmigungspflicht für neue Produkte ermächtigt wiederum nicht den Staat, sondern verpflichtet die privatwirtschaftlichen Produktentwickler. Mit den geplanten Vorgaben an das Produktdesign, ergänzt durch Vertriebsverbote außerhalb der Zielgruppe, könnte die Qualitätskontrolle von Finanzprodukten künftig europäisches Recht werden.

Im deutschen Recht findet eine Qualitätskontrolle von Finanzprodukten bislang nur in Ansätzen statt. ${ }^{189}$ Dabei steht das hierfür notwendige Instrumentarium im Zivilrecht bereits zur Verfügung, nämlich die Nichtigkeit von Produktbedingungen $(\$ 138 \mathrm{BGB})$ und deren AGB-Kontrolle ( $\$ \$ 305 \mathrm{ff} \mathrm{BGB})$. In Sachen "Zinswette“ lehnte das OLG Frankfurt als Berufungsgericht zwar einen Verstoß gegen die guten Sitten ab, zog eine AGB-Kontrolle aber zumindest in Betracht. ${ }^{190}$ Der BGH umschiffte die $\$ \$ 138,305 \mathrm{ff} B G B$, indem er direkt auf den Verstoß gegen die Beratungspflicht rekurrierte. ${ }^{191}$ Zivilrechtliche Folgefragen können an dieser Stelle nur aufgeworfen werden, etwa ob die Genehmigungspflicht und das Vertriebsverbot als Schutzgesetze i. S.d. $\$ 823$ Abs. 2 BGB zu qualifizieren wären. Offen ist auch, ob Verstöße gegen diese Pflichten oder aufsichtsrechtliche Produktverbote die zivilrechtliche Nichtigkeit $\left(\$ 134\right.$ BGB) des Kaufvertrags bewirken. ${ }^{192}$

187 Kommission, Impact Assessment MiFID II, Working Paper v. 20. 10. 2011, SEC (2011) 1226, S. 44 f. Ablehnend auch Spindler, 34 J. Consum. Policy 315, 327 f (2011). S. auch Köndgen, FS Hopt, Bd. II, 2010, 2113, 2140; DERs, BKR 2011, 283, 286; BuCK-HeEB, ZHR 177 (2013), 310, 342; MÜLBERT, ZHR 177 (2013), 160, $199 \mathrm{f}$.

188 Die Eingriffsvoraussetzungen sollen durch Kommissionsrechtsakte konkretisiert werden, vgl. Art. 31 Abs. 8, 32 Abs. 6 i. V.m. Art. 41 MiFIR-E (Fn. 5). Konkretisierungsbedürftig ist insbesondere, in welchen Fällen die „Gefahren für den Anlegerschutz“ groß genug sind, um Produktinterventionen zu rechtfertigen.

189 Vgl. OLG Frankfurt, Urt. v. 29.7.2009, WM 2009, 1563; OLG Bamberg, Urt. v. 11.5. 2009, ZIP 2009, 1209, 1211.

190 OLG Frankfurt, Urt. v. 30.12.2009, ZIP 2010, 921, 922 f: Die Erforderlichkeit einer AGB-Kontrolle wurde verneint, da ein geschäftserfahrenes Unternehmen nicht in gleichem Maße schutzbedürftig sei wie ein Verbraucher. Zu $\$ 138$ BGB stellte das Gericht fest, dass die Privatautonomie den Abschluss risikoreiche Geschäfte auch dann gestatte, wenn ein Gewinn nur unter günstigen Umständen zu erzielen gewesen sei.

191 BGH, Urt. v. 22.3.2011, BGHZ 189, 13 Rdn. 17 f.

192 Hierzu CAHn/Müchler, BKR 2013, 45, 54 f. 


\section{g) Regulierung von Interessenkonflikten}

Hinsichtlich des Zuwendungsverbots des $₫ 31 \mathrm{~d}$ Abs. 1 WpHG ergibt sich ein gemischtes Bild: Zurecht wurde die Vermutungsregel des $₫ 31 \mathrm{~d}$ Abs. 4 WpHG a. F. kritisiert, wonach Zuwendungen bei der Anlageberatung stets der Qualitätsverbesserung dienten, denn damit hatte der deutsche Gesetzgeber ausgerechnet den „interessenkonfliktträchtigsten Fall“ vom Verbot der Vorteilsannahme wieder freigestellt. ${ }^{193}$ Die Streichung von $\$ 31 \mathrm{~d}$ Abs. 4 WpHG a.F. 2011 war daher zu begrüßen. ${ }^{194}$ Allerdings wiegt $\$ 31 \mathrm{~d}$ WpHG den Kunden weiterhin in trügerischer Sicherheit. ${ }^{195}$ Weniger hilfreich als gedacht ist die Offenlegung von Anreizzahlungen, $\$ 31$ d Abs. 1 Satz 1 Nr. 2 WpHG: Die anlegerschützende Aufklärungspflicht wird dadurch „verwässert", dass $\ 31 \mathrm{~d}$ Abs. 3 WpHG den Wertpapierfirmen gestattet, den Kunden lediglich eine Zusammenfassung der wesentlichen Bestandteile der Zuwendungsvereinbarungen vorzulegen. ${ }^{196}$ Zudem zeigen empirische Untersuchungen, dass die Offenlegung von Provisionen Anleger dazu verleitet, von der Neutralität der Wertpapierfirma auszugehen, anstatt die Geschäftsbeziehung kritisch zu überdenken. ${ }^{197}$ Auch die weiterhin bestehende Ausnahme für Zuwendungen, die auf Qualitätsverbesserungen ausgelegt sind ( $\$ 31 \mathrm{~d}$ Abs. 1 Satz 1 Nr. 1 WpHG), steht nach wie vor in berechtigter Kritik. ${ }^{198}$ Grundsätzlich braucht es schärferer Schwerter wie z. B. Provisionsverbote, um Interessenkonflikte zwischen Wertpapierfirma und Kunde wirkungsvoll einzudämmen. ${ }^{199}$

\section{b) Das Anlegerleitbild: zwischen verständigem und schutzbedürftigem Anleger}

Um eine rationale Anlegerentscheidung zu ermöglichen, vertraute der Gesetzgeber vor allem auf abstrakte, standardisierte Aufklärung. Im Vergleich zum

193 So Assmann, ÖBA 2007, 40, 51. S. auch Fuchs, aaO (Fn. 16), §31 d WpHG Rdn. 29; Möllers, aaO (Fn. 126), $\$ 31 \mathrm{~d}$ WpHG Rdn. 10, 42.

194 Art. 1 Nr.7 AnsFuG, BGBl. I 2011, S. 538. Auch die Gesetzesbegründung verweist darauf, dass in der Aufsichtspraxis die Vermutensregel kaum widerlegt werden konnte, vgl. Begr RegE z. AnsFuG, aaO (Fn. 12), S. 22. S. Möllers/Wenninger, NJW 2011, $1697,1699$.

195 So mit deutlichen Worten SETHe, FS Nobbe, 2009, S. 769, $773 \mathrm{ff}$.

196 Kritsch insofern Koller, aaO (Fn. 7), \$31 d WpHG Rdn. 47; Habschick/Evers, aaO (Fn. 151), S. 55. A. A. Fuchs, aaO (Fn. 16), $\$ 31$ d WpHG Rdn. 42, der die Vorschrift für sinnvoll hält, um einen „information overkill“ zu vermeiden; KocH, aaO (Fn. 126), \31 d WpHG Rdn. 53; Möllers, aaO (Fn.126), \31 d WpHG Rdn. 54 („gewisse Erleichterung“); LANG/KüHNE, WM 2009, 1301, 1305.

197 SPINDLER, NJW 2011, 1920, 1923.

198 S. Koller, aaO (Fn. 7), $\$ 31$ d WpHG Rdn. 29.

199 Hierzu sogleich unten III.2.d). 
Erfordernis konkret-individueller Aufklärung vor dem FRUG eine Verschlechterung des Anlegerschutzes. Zwar wird zunehmend auf vereinfachte Informationen gesetzt. Der Verzicht auf zusätzlichen Schutz, wie etwa durch Schriftformerfordernisse, deutet de lege lata auf das Leitbild des verständigen Anlegers hin, der Standardinformationen und Informationsblätter liest, Risiken erkennt und rational handelt. Die in der Realität beschränkte Rationalität der Anleger berücksichtigen hingegen die Gestaltungsoptionen zur Wiedereinführung individueller Informationen und die Vorschriften zur Produktregulierung de lege ferenda besser.

\section{Anlegerbezogene Beratung}

\section{Regelungsziel}

Bereits aus dem Wortlaut der WpDiRiL von 1993 ergab sich, dass Anlageempfehlungen im „bestmöglichen Interesse“ des Kunden liegen müssen. ${ }^{200}$ Hiervon unabhängig definierte der BGH 1993 in dem „Bond“-Urteil ${ }^{201}$ die Grundpflichten der zivilrechtlichen Anlageberatung, als deren gesetzliche Grundlage mit Verabschiedung des WpHG 1994 das Merkmal der „Erforderlichkeit" (\$31 Abs. 2 Satz 1 WpHG a. F.) herangezogen wurde. ${ }^{202}$ Durch MiFID I und FRUG wurden die Pflichten der Anlageberatung schließlich auch gesetzlich normiert. Das Regelungsziel der anlegerbezogenen Beratung unterscheidet sich vom Ziel der rationalen Anlageentscheidung in drei Punkten: (1.) Anstelle abstrakter, standardisierter Informationen müssen dem Kunden alle Informationen mitgeteilt werden, die er benötigt, um die spezifischen Anlagerisiken des konkret empfohlenen Finanzprodukts verstehen und einschätzen zu können. ${ }^{203}$ (2.) Die Geeignetheitsprüfung ( $\$ 31$ Abs. 4 Satz 2 WpHG) geht über die Angemessenheitsprüfung insofern deutlich hinaus, als sich die Geeignetheit des konkreten Anlageprodukts auf die konkreten Kenntnisse und Erfahrungen des Kunden und dessen finanzielle Risikotragfähigkeit ${ }^{204}$

200 S. Art. 11 Abs. 1 Satz 4, 1. Spiegelstrich RiL 93/22/EWG des Rates v. 10.5.1993 über Wertpapierdienstleistungen, ABl. EG Nr. L 141, S. 27. Hierzu Koller, aaO (Fn. 69), \31 WpHG Rdn. 172.

201 BGH, Urt. v. 6. 7.1993, BGHZ 123, 126, $128 \mathrm{ff}$ - Bond.

202 Zur Parallelität der Informationspflicht aus $₫ 31$ Abs. 2 Satz 1 WpHG zur anleger- und objektgerechten Beratung des BGH Möllers, aaO (Fn. 126), $\$ 31$ WpHG Rdn. 259; s. Wieneke, Discount-Broking und Anlegerschutz, 1999, S. 115.

203 Zur konkreten Aufklärungspflicht des Zivilrechts Lenenbach, aaO (Fn. 8), Rdn. 11.255; Möllers/Ganten, ZGR 1998, 773, 788 f. Aufsichtsrechtlich ist das Bestehen einer konkreten Informationspflicht umstritten, diese bejahend FucHs, aaO (Fn. 16), \$31 WpHG Rdn. 255; Einsele, JZ 2008, 477, 481 f; a. A. Mülbert, WM 2007, 1149, 1156; VeIL, ZBB 2008, 34, $38 \mathrm{f}$.

204 Zum Prüfungsumfang $\ 6$ Abs. 1 Nr. 1 WpDVerOV. 
beziehen muss. (3.) Auf dieser Grundlage ist eine persönliche Empfehlung für ein konkretes Finanzprodukt abzugeben. ${ }^{205}$ Die Anlageberatung ist daher auch nach WpHG-Maßgabe stets anlegerbezogen. Von der Vermögensbetreuung $^{206}$ unterscheidet sich die Anlageberatung dadurch, dass bei der Anlageberatung weiterhin der Kunde die Anlageentscheidung selbst und eigenverantwortlich treffen muss. ${ }^{207}$

\section{Instrumente}

\section{a) Geeignetheitsprüfung}

Die durch die MiFID I eingeführte Geeignetheitsprüfung ${ }^{208}$ verpflichtet nicht zur „bestmöglichen“ Wahrung der Kundeninteressen bei der Erteilung der Anlageempfehlung. ${ }^{209}$ Vielmehr genügt die Empfehlung den gesetzlichen Anforderungen bereits dann, wenn das Produkt den Anlagezielen (Anlagedauer, Risikobereitschaft, Zweck der Anlage ${ }^{210}$ und der Leistungsfähigkeit des Kunden entspricht und er die Risiken verstehen kann. ${ }^{211}$ Weitergehende, fiduziarische Pflichten gelten bei gleicher Eignung mehrerer Produkte: In einem solchen Fall ist dasjenige Produkt zu empfehlen, das am besten die erkennbaren Interessen des Kunden wahrt. ${ }^{212}$ Die MiFID II-Fassung des EU-Parlaments sieht nun vor, dass bei Empfehlung eines Produktpakets jeder einzelne Bestandteil und auch das Paket insgesamt für den Kunden geeignet sein muss. $^{213}$

\section{b) Individuelle Informationen}

Sowohl der durch die „Bond“-Rechtsprechung ausgestaltete zivilrechtliche Anlageberatungsvertrag als auch die auf der MiFID I beruhenden WpHG-

205 Braun/Lang/Loy, in: Ellenberger/Schäfer/Clouth/Lang, 4. Aufl., 2011, MiFIDPraktikerhandbuch, Rdn. 301.

206 Unten V.1.

207 SEThe, Anlegerschutz im Recht der Vermögensverwaltung, 2005, S.26f; MöLlers, WM 2008, 93; Fuchs, aaO (Fn. 16), $\$ 31$ WpHG Rdn. 244.

208 Art. 19 Abs. 4 MiFID I.

209 Anders als noch Art. 11 Abs. 1 Satz 4, 1. Spiegelstrich WpDiRiL (Fn. 199).

210 Vgl. $\$ 6$ Abs. 1 Nr. 2 WpDVerOV.

211 Koller, aaO (Fn. 7), \31 WpHG Rdn. 151. S. Fuchs, in aaO (Fn. 16), $\$ 31$ WpHG $\mathrm{Rdn} .257 \mathrm{ff}$.

212 Koller, aaO (Fn. 7), \31 WpHG Rdn. 151, 17.

213 Art. 25 Abs. 1 Satz 2, Abs. 2 Satz 2 MiFID II-E (EUP) (Fn. 4).Für Kleinanleger ist anzugeben, ob die Paketbestandteile auch einzeln erworben werden können und welche Kosten jeweils anfallen, Art. 24 Abs. 7 Satz 1 MiFID II-E (EUP) (Fn. 4). 
Pflichten verpflichten die Wertpapierfirma dazu, dem Kunden individuelle Informationen und Empfehlungen zu erteilen.

aa) Dependenz der Rechtsquellen: EuGH-Urt. v. 30. 5. 2013

Höchstrichterlich war lange Zeit ungeklärt, in welchem Verhältnis die Rechtsquellen der Anlageberatung (MiFID I, WpHG und richterrechtlicher Pflichtenkanon) zueinander stehen. Der BGH hatte sich hierzu zwar 2012 in seinen „Lehman-Entscheidungen“ geäußert. ${ }^{214}$ Die Ausführungen zum Europarecht ${ }^{215}$ wurden aber als weitgehend verfehlt beurteilt. ${ }^{216}$

Auch weiterhin wurde daher im Schrifttum kontrovers diskutiert, ob der europäische Gesetzgeber mit der MiFID I zugleich die Vollharmonisierung des Zivilrechts intendiert hatte. ${ }^{217}$ Unabhängig davon, ob man die $\mathbb{S} 31 \mathrm{ff} \mathrm{WpHG}$ als ausschließlich aufsichtsrechtliche Normen, Normen mit „Doppelnatur“ oder als Aufsichtsrecht mit „Ausstrahlungswirkung“ auf das Zivilrecht begreift, ${ }^{218}$ entfalteten dieser Auffassung zufolge die Vorgaben der MiFID I im Wege richtlinienkonformer Auslegung unmittelbare Wirkung auch für das nationale Zivilrecht. Anders urteilte indes am 30. 5. 2013 der EuGH. ${ }^{219}$ Aufgrund mehrerer Vorlageverfahren der spanischen Zivilgerichtsbarkeit galt es zu klären, ob ein Verstoß gegen die MiFID I-Wohlverhaltensregeln zivilrechtliche Folgen zeitigen muss. ${ }^{220}$ Der zugrunde liegende Sachverhalt ereignete sich im

214 Vgl. BGH, Urt. v. 27. 9. 2011, NJW 2012, 66, 70 f Rdn. 45 ff; Urt. v. 27. 9. 2011, NJWRR 2012, 43, 47 f Rdn. 48 ff; Urt. v. 26. 6. 2012, NJW 2012, 2873, 2874 f Rdn. 24 ff Lehman I-III. Statt aller wird nur die jüngste Entscheidung zitiert.

215 BGH, Urt. v. 26. 6. 2012, NJW 2012, 2873, 2874 f Rdn. 24 f.

216 Bspw. Roth, ZBB 2012, 429, 430 ff; Herresthal, ZBB 2012, 89, $102 \mathrm{ff}$.

217 Hierfür MülBERT, ZHR 172 (2008), 170, 183 ff; DERs., WM 2007, 1149, 1157; DERs. in: Ferrarini/Wymeersch, Investor Protection in Europe: Corporate Law Making, The MiFID and Beyond, 2006, S.299, 318 f; Enriques, ebd., S. 321, 323; Herresthal, ZBB 2009, 348, 352; DERs., ZBB 2012, 89, 102 f; Nikolaus/D'Oleire, WM 2007, 2129, 2134; SETHe, FS Nobbe, 2009, S. 769, 786 f; für eine partielle Vollharmonisierung im Bereich der MiFID I-DRiL Roth, ZBB 2012, 429, 437 f; a. A. Koller, a. a. O. (Fn. 7), Vor $\$ 31$ WpHG Rdn. 5; Assmann, FS Schneider, 2011, S.37, 51 ff; Ders., ZIP 2009, 2125, 2126; Schwark, a. a. O. (Fn. 50), Vorbem. $\$ \$ 31 \mathrm{ff}$ WpHG Rdn. 14; Koch, ebd., \31 a WpHG Rdn. 60; Ellenberger, FS Nobbe, 2009, S. 523, 535 ff; Veil, WM 2009, 1585, 1587; Podewils/Reisch, NJW 2009, 116, 120.

$218 \mathrm{Zu}$ diesem Meinungsstreit Möllers, aaO (Fn. 130), $\$ 31$ WpHG Rdn. $10 \mathrm{ff}$.

219 EuGH, Urt. v. 30. 5. 2013, Rs. C-604/11 - Genil.

220 Jeweils Vorlagefragen Nr. 2 und 3: Juzgado Mercantil de Barcelona v. 18. 7. 2011, Rs. C-381/11, ABl. 2011 Nr. C 290 v. 1.10.2011, S. 3 (inzwischen zurückgezogen: vgl. Verfügung v. 12.1. 2012 sowie ABl. 2012 Nr. C 73/25 v. 10. 3. 2012); Juzgado de Primera Instancia no 12 de Madrid v. 28. 11. 2011, Rs. C-604/11, ABl. 2012 Nr. C 32 v. 4. 2. 2012, S. 15 f; Juzgado Mercantil de Barcelona v. 30.12. 2011, Rs. C-664/11, ABl. 2012 Nr. C 80 v. 17.3.2012, S. 11; Juzgado Mercantil de Barcelona v. 30.12.2011, Rs. C-665/11, 
September 2008 und damit nach Ablauf der MiFID I-Umsetzungsfrist ${ }^{221}{ }^{222}$ Das Gericht kam zum Schluss, dass die MiFID I die Mitgliedstaaten nicht dazu verpflichte, Verstöße gegen die Wohlverhaltensregeln auch mit zivilrechtlichen Sanktionen zu belegen.223 Vielmehr stehe es im Ermessen der Mitgliedsstaaten, ob und ggf. welche zivilrechtlichen Folgen hierfür vorgesehen werden. ${ }^{224} \mathrm{Im}-$ plizit bringt der EuGH hierdurch zum Ausdruck, dass der europäische Gesetzgeber mit Verabschiedung der MiFID I nicht zugleich das nationale Zivilrecht der Mitgliedstaaten harmonisieren wollte. ${ }^{225}$ Konsequenz dieser richtungsweisenden Entscheidung ist, dass die MiFID I nicht qua richtlinienkonformer Auslegung bei der Auslegung des Zivilrechts zu berücksichtigen ist, sondern es den Mitgliedstaaten überlassen bleibt, die mit der MiFiD verbundenen zivilrechtlichen Fragestellungen überschießend zu harmonisieren.

\section{bb) Nationale Rechtsprechung}

Aufgrund zunehmender Divergenz der Pflichtenstandards im Aufsichts- und Zivilrecht ${ }^{226}$ bleibt die höchstrichterliche Klärung der Frage nach der (ziviloder aufsichtsrechtlichen) Rechtsnatur der $\$ \mathbb{S} 31 \mathrm{ff}$ WpHG weiterhin dringend geboten. So hatte der BGH die Banken im Zinswette-Urteil 2011 dazu verpflichtet, den Anleger hinsichtlich des eingegangenen Geschäftsrisikos ${ }^{227}$ auf den „gleichen Wissens- und Kenntnisstand“ zu bringen, wie ihn die beratende Bank selbst besitzt. ${ }^{228}$ Dieses hochgesteckte Ziel kann in der Beratungspraxis nicht erfüllt werden. ${ }^{229}$ Losgelöst vom Korsett der Informationspflichten, auf das der BGH zurückgreifen musste, wurden in Großbritannien Anlageberater

ABl. 2012 Nr. C 80 v. 17.3.2012, S. 12. Hinweise hierzu bei Grundmann, WM 2012, $1745,1752$.

221 Am 31.1.2007, vgl. Art. 70 MiFID (Fn.2) I i.V.m. Art. 53 Abs. 1 MiFID I-DRiL (Fn. 108).

222 EuGH, Urt. v. 30. 5.2013, Rs. C-604/11 Tz. 15.

223 EuGH, Urt. v. 30. 5. 2013, Rs. C-604/11 Tz. 57. Hierzu auch Möllers, aaO (Fn. 130), $\S 31 \mathrm{WpHG}$ Rdn. 23.

224 Ebd.

225 Möllers, in: Gsell/Herresthal (Hrsg.), Vollharmonisierung im Privatrecht: die Konzeption der Richtlinie am Scheideweg?, 2009, S. 247 ff. S. auch Koller, aaO (Fn. 7), Vor $₫ 31 \mathrm{WpHG}$ Rdn. 5.

226 S. die Beispiele bei Buck-HeEs, ZHR 177 (2013), 310, $316 \mathrm{ff.}$

227 Richtigerweise ist auf das Risiko des Produkts abzustellen, nicht aber auf dessen finanzmathematischen Grundlagen, vgl. Buck-Неes, ZHR 177 (2013), 310, 332. So aber Grundmann, WM 2012, 1745, 1747; Köndgen, BKR 2012, 283: „Man darf deshalb getrost unterstellen, dass nicht einmal jeder durchschnittlich befähigte Kundenberater zwischen Konstanz und Flensburg das kunstvolle Design dieser Produkte zur Gänze durchschaut hat.“.

228 BGH, Urt. v. 22.3.2011, BGHZ 189, 13, 25 f Rdn. 29.

229 Kritisch Sснмітт, BB 2011, 2824, 2826; i.E. wohl auch KLöнN, ZIP 2011, 762, 763; LEHMANN, JZ 2011, 749, 750 ff. 
bereits 2009 durch die FSA dazu verpflichtet, Produktempfehlungen nur dann abzugeben, wenn sie das Produkt und dessen Struktur vollständig verstanden haben. ${ }^{230}$

\section{c) Beratungsprotokolle und Angemessenheitsberichte}

Ebenso wie die Produktinformationsblätter beruhen auch die Beratungsprotokolle ( $\$ 34$ Abs. 2 a WpHG) auf einem Alleingang des nationalen Gesetzgebers, ${ }^{231}$ der hiermit zwei Zielsetzungen verfolgte: Der BaFin sollte die Aufsicht über die Wertpapierfirmen erleichtert werden und den Kunden ein Beweismittel an die Hand gegeben werden, um zivilrechtliche Ansprüche bei Fehlberatung durchsetzen zu können. ${ }^{232}$ Eine vergleichbare Stoßrichtung lässt sich dem „Angemessenheitsbericht“ der MiFID II zugrunde legen, der den Anlageberatungskunden darüber informieren soll, wie die Beratung auf seine persönlichen Merkmale abgestimmt wurde. ${ }^{233}$ Sinnvollerweise möchte das EU-Parlament die Angemessenheitsberichte auf die Kleinanlegerberatung beschränken, ${ }^{234}$ professionelle Anleger benötigen diese Hilfestellung nicht.

\section{d) Qualitätskontrolle einzelner Finanzintermediäre}

Die Qualitätskontrolle wird in Zukunft über die Aufklärungs- und Beratungsdienstleistung hinaus auf die fachliche Eignung der Leitungsorgane und Kundenberater ausgedehnt. Wertpapierfirmen müssen durch geeignete Complian-

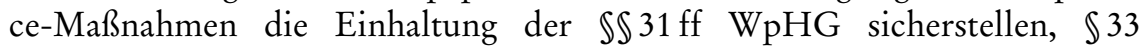
WpHG. ${ }^{235}$ Auch die Einhaltung der Vorgaben für die Anlageberatung unterliegt der ex post-Kontrolle der $\$ \mathbb{S} 35,36$ Abs. 4 WpHG.

Erstmals stellte die AIFM-RiL Anforderungen an die Verwalter (AIFM) alternativer Investmentfonds (AIF) auf, u. a. Zulassungsvoraussetzungen und

230 FSA, Using the FSA's structured investment product advice suitability assessment template, Oktober 2009, abrufbar unter http://www.fsa.gov.uk/pubs/other/sip_ template_guidance.pdf, S. 7: „Advisers should ensure they fully understand the product and how it is structured“. S. Köndgen, FS Hopt, Bd. II, S. 2113, 2135.

231 \34 d Abs. 2 a WpHG, eingefügt durch Art. 4 Nr. 4 SchVG v. 31.7.2009, BGBl. I, S. 2512.

232 RegE z. SchVG v. 29. 4. 2009, BT-Drucks. 16/12814, S. 14, 27 f; FrAncK, BKR 2012, 1, 2.

233 Art. 25 Abs. 5 Satz 3 MiFID II-E (Fn. 3). Gibt die Wertpapierfirma an, regelmäßig die Eignung der empfohlenen Produkte nachzuprüfen, ist zusätzlich anzugeben: Häufigkeit der Beurteilung, Fortbestand der Produkteignung und Wertentwicklung, Art. 25 Abs. 5 Satz 4 MiFID II-E (EUP) (Fn. 4).

234 Art. 25 Abs. 5 Satz 1, 3 MiFID II-E (EUP) (Fn. 4).

235 Oben II.c)aa) und bb). 
Vergütungsregeln. ${ }^{236}$ Diese werden in Deutschland durch das KAGB ${ }^{237}$ umgesetzt. Ebenso sollen nach der MiFID II die Leitungsorgane der Wertpapierfirmen Vorgaben in Bezug auf ihren Leumund, ihre fachlichen Fähigkeiten und Erfahrungen und ihr zeitliches Engagement erfüllen müssen. ${ }^{238}$ Der MiFID II-Entwurf des EU-Parlaments sieht zudem vor, dass die Position eines „nicht geschäftsführenden“ bzw. externen Direktors einzuführen ist, der die Einhaltung der Compliance-Vorgaben auf Leitungsebene überwachen soll.239 Doppelfunktionen sollen beschränkt ${ }^{240}$ und die Leitungsorgane bei Verstößen persönlich (straf- und zivilrechtlich) zur Verantwortung gezogen werden können, unabhängig vom nationalen Rechtssystem ${ }^{241}$.

Das EU-Parlament will die Wertpapierfirmen im Zuge der MiFID II ex ante zum Nachweis verpflichten, dass die Kundenberater über die für die Anlageberatung erforderlichen Kenntnisse und Kompetenzen verfügen und die zur Beurteilung maßgeblichen Kriterien veröffentlichen. ${ }^{242}$ Bislang unterliegen Anlageberater nur in Großbritannien ${ }^{243}$ vergleichbaren Pflichten, in Deutschland ist ein Sachkundenachweis für den Vertriebsbeauftragten ( $\$ 34 \mathrm{~d}$ Abs. 2 WpHG) und für Anlageberater ( $\$ 34 \mathrm{~d}$ Abs. 1 Satz $1 \mathrm{WpHG}$ ) vorgesehen ${ }^{244}$. Eine Registrierungspflicht ( $(34 \mathrm{~d} \text { Abs. } 1 \mathrm{WpHG})^{245}$ ist auf europäischer Ebene nicht in Sicht.

\section{e) Interessenkonflikte von Wertpapierdienstleistungsfirmen, Kundenberatern und Honorarberatung}

Bei der Anlageberatung müssen persönliche Einschätzungen, die nur eingeschränkt überprüfbar sind, ${ }^{246}$ abgegeben werden, so dass aufgrund finanzieller Eigeninteressen der Wertpapierfirmen und ihrer Kundenberater ein besonders

236 Hierzu Möllers/Harrer/Krüger, WM 2011, 1537, 1539 ff; Bussalb/UnZicker, BKR 2012, 309, $310 \mathrm{ff}$.

237 RegE KAGB v. 12.12.2012, BR-Drucks. 791/12, S.1. S. Möllers, NJW 52/2012, Editorial.

238 Art. 9 Abs. 1 Satz 1, Abs. 3 MiFID II-E (EUP) (Fn. 4).

239 Art. 9 Abs. -1 MiFID II-E (EUP) (Fn. 4).

240 Art. 9 Abs. 1 Satz 2 lit. a MiFID II-E (EUP) (Fn. 4).

241 Art. 9 Abs. 8 a MiFID II-E (EUP) (Fn. 4).

242 Art. 25 Abs. -1 MiFID II-E (EUP) (Fn. 4).

243 Überblick für Großbritannien abrufbar unter http://www.fsa.gov.uk/about/what/rdr/ firms/professionalism.

244 Hierzu Möllers, aaO (Fn. 126), $\$ 34$ d WpHG Rdn. 1 ff.

245 Für Honorarberater sieht der Gesetzgeber eine eigenständige Registrierungspflicht vor, vgl. $\$ 36$ c WpHG i.d.F. gemäß Art. 1 Nr. 5 RegE v. 21.12.2012 eines Gesetzes zur Förderung und Regulierung einer Honorarberatung über Finanzinstrumente, BRDrucks. 814/12 („Honoraranlageberatungsgesetz“).

246 S. oben IV.2.a). 
großes Potential für Interessenkonflikte besteht. ${ }^{247}$ Bereits die WpDiRiL verpflichtete die Wertpapierfirmen daher zur „bestmöglichen“ Wahrung der Kundeninteressen, ${ }^{248}$ noch deutlicher die MiFID I ${ }^{249}$.

Auf das Zuwendungsverbot und dessen Ausnahmen ( $\$ 31 \mathrm{~d}$ WpHG) wurde bereits oben eingegangen. ${ }^{250}$ Die MiFID II will den Mitgliedsstaaten Gestaltungsspielräume einräumen, um die Ausnahmen vom Zuwendungsverbot weiter einschränken zu können: Die Zulässigkeit von Provisionszahlungen bei der Anlageberatung und Portfolioverwaltung kann ganz untersagt ${ }^{251}$ und Wertpapierfirmen können dazu verpflichtet werden, Provisionen generell an ihre Kunden weiterzugeben. ${ }^{252}$

Provisionsbasierte Vergütungssysteme verleiten Kundenberater dazu, anstelle des bestgeeigneten Produkts dasjenige mit der höchsten Vertriebsprovision zu empfehlen. Von diesem Missstand will die MiFID II Abhilfe schaffen: Grundsätzlich darf das verwendete Vergütungssystem der Verpflichtung nicht entgegenstehen, im besten Anlegerinteresse zu handeln. ${ }^{253}$ Eine vergleichbare Vorschrift findet sich bereits im WpHG ( $\$ 33$ Abs. 1 Satz 2 Nr. 3 a WpHG). ${ }^{254}$ Für die Beratung und den Verkauf an Kleinanleger sieht die MiFID II die Sonderregel vor, dass die Vergütungsstruktur den Kundenberater nicht darin beeinträchtigen darf, objektive Empfehlungen und verständliche Informationen zu erteilen. ${ }^{255}$ Die Vergütung soll nicht in erster Linie von Verkaufszielen oder vom Ertragswert der empfohlenen Produkte abhängen. ${ }^{256}$ Bei der Beratung von Kleinanlegern darf auch die Leistungsbeurteilung des Beraters keinen Anreiz dafür setzen, ein bestimmtes Produkt zu empfehlen, wenn ein anderes Produkt grundsätzlich besser geeignet wäre. ${ }^{257}$

Mit der MiFID II wird erstmals auf europäischer Ebene zwischen „abhängiger“ und „unabhängiger“ Anlageberatung unterschieden. Bislang sah nur das britische Aufsichtsrecht eine entsprechende Differenzierung vor. ${ }^{258}$ Provisionszahlungen an „unabhängige“ Anlageberater sollen generell untersagt werden. ${ }^{259} \mathrm{Bei}$

247 Möllers, FS Hopt, S. 2247, 2250.

248 Art. 11 Abs. 1 Satz 4, 1. Spiegelstrich WpDiRiL (Fn. 200).

249 Vgl. Art. 19 Abs. 1 MiFID I (Fn. 2): „ehrlich, redlich und professionell im bestmöglichen Interesse des Kunden“.

250 Oben III.2.d).

251 Art. 24 Abs. 5 Satz 1 MiFID II-E (EUP) (Fn. 4).

252 Art. 24 Abs. 1 c Satz 2, Abs. 5 Satz 2 MiFID II-E (EUP) (Fn. 4).

253 Art. 24 Abs. 1 b Satz 1 MiFID II-E (EUP) (Fn. 4).

254 Hierzu Koller, aaO (Fn. 7), \33 WpHG Rdn. 78 ff.

255 Art. 24 Abs. 1 b Satz 2 MiFID II-E (EUP) (Fn. 4).

256 Art. 24 Abs. 1 b Satz 3 lit. a MiFID II-E (EUP) (Fn. 4).

257 Art. 24 Abs. 1 b Satz 3 lit. b MiFID II-E (EUP) (Fn. 4).

258 Rules 6.2A.3, 6.2A.4A COBS, abrufbar unter http://fsahandbook.info/FSA/html/ bandbook/COBS/6/2A.

259 Art. 24 Abs. 5 lit. ii MiFID II-E (Fn. 3). 
der Anlageberatung soll darüber informiert werden müssen, ob die Beratung „unabhängig" erbracht wird, und, falls dies der Fall ist, in welchem Umfang eine Marktanalyse durchgeführt wurde. ${ }^{260}$ Bei der „unabhängigen“ Anlageberatung müssen Empfehlungen auf der Bewertung einer ausreichenden Produktanzahl beruhen. Es darf sich nicht ausschließlich um Produkte der Wertpapierfirma oder nahestehender Anbieter handeln. ${ }^{261}$ Auch der deutsche Gesetzgeber will mit dem Honoraranlageberatungsgesetz Kunden die bewusste Entscheidung zwischen provisionsbasierter und Honorarberatung ermöglichen. ${ }^{262}$ So ist die Verankerung zusätzlicher Verhaltens- ${ }^{263}$ und Organisationspflichten ${ }^{264}$ für Wertpapierfirmen geplant, welche die Anlageberatung in der Form der Honorar-Anlageberatung erbringen möchten. ${ }^{265}$

\section{Bewertung}

\section{a) Geeignetheitsprüfung und Beratungspflichten}

Nicht zuletzt der EuGH könnte der immer weitergehenden Verschärfung der Aufklärungs- und Beratungspflichten durch die deutschen Zivilgerichte einen Riegel vorschieben, wenn das Gericht zum Schluss kommt, dass die MiFID I auch zivilrechtliche Wirkungen zeitigt ${ }^{266}$. Entscheidungen wie das „Zinswette“-Urteil, die das Anlagerisiko des Kunden zum Verständnisrisiko der beratenden Bank machen - die Bank wird aus ihrer Verantwortung kraft Informationsüberlegenheit nur dann entlassen, wenn die Beratung auch einen

260 Art. 24 Abs. 3 Satz 1, 1. Spiegelstrich MiFID II-E (Fn. 3).

261 Art. 24 Abs. 5 lit. i MiFID II-E (Fn. 3).

262 So explizit der RegE z. Honoraranlageberatungsgesetz, aaO (Fn. 245), S. 1.

263 Informationspflichten ( $\$ 31$ Abs. $4 \mathrm{~b}$ Nr. 1 WpHG-E), Pflichten in Bezug auf den materiellen Inhalt der Anlageempfehlung ( $\$ 31$ Abs. 4 b Nr. 2 WpHG-E), Annahmeverbote für nicht-monetären Zuwendungen ( $\$ 31$ Abs. 4 b Nr.3 Satz 2 WpHG-E), Pflichten in Bezug auf die bedingte Annahme für monetäre Zuwendungen $(\mathbb{S} 31$ Abs. 4 b Nr. 3 Satz 3 WpHG-E), zusätzliche Informationspflichten bei Verdacht von Interessenkonflikten ( $\$ 31$ Abs. 4 c Satz 1 WpHG-E), sowie Pflichten im Zusammenhang mit der Art des Geschäftsabschlusses ( $\$ 31$ Abs. 4 c S 2 WpHG-E).

264 Pflichten, welche eine organisatorische, funktionale und personelle Trennung zwischen den Bereichen der provisionsgestützten Anlageberatung und der Honorar-Anlageberatung innerhalb eines Unternehmens vorsehen ( $\$ 33 \mathrm{Abs} .3$ a Satz $1 \mathrm{WpHG}-\mathrm{E}$ ), zusätzliche Pflichten in Bezug auf die Vertriebsvorgaben i.S.d. $\$ 31$ Abs. 1 Nr.3 a WpHG, ( $(33$ Abs. 3 a Satz 2 WpHG-E) sowie Abgabepflichten in Bezug auf den Internetauftritt ( $\$ 33$ Abs. 3 a Satz 3 WpHG-E). Ferner sind die Errichtung eines Honorar-Anlageberaterregisters $(\$ 36 \mathrm{c}$ WpHG-E) und ein Bezeichnungsschutz für den Begriff „Honorar-Anlageberatung“ ( $\$ 36 \mathrm{~d}$ WpHG-E) geplant.

265 Hierzu Möllers, aaO (Fn. 126), \$31 WpHG Exkurs: Honoraranlageberatungsgesetz.

266 S. oben IV.2.b)aa). 
„Verständniserfolg“ erzielt ${ }^{267}$ - könnten in der Folge wohl nicht aufrechterhalten werden. Möglicherweise wird die allgemeine Tragweite dieser Entscheidung ohnehin überschätzt, schließlich lag dem Urteil ein hochkomplexer Zins-Swap-Vertrag zugrunde. Der BGH äußerte sich (wohlweislich) nicht dazu, welche anderen Produkte eine vergleichbare Komplexität aufweisen könnten. ${ }^{268}$

Positiv zu bewerten sind die geplanten Angemessenheitsberichte, welche die Geeignetheit der Empfehlung im Nachhinein überprüfbar machen und damit eine dem deutschen Beratungsprotokoll vergleichbare Funktion erfüllen. ${ }^{269}$ Ebenso zu begrüßen ist der Vorschlag, dass sich die Geeignetheitsprüfung künftig sowohl auf das gesamte Produktpaket als auch die einzelnen Produkte beziehen muss, schließlich erhöhen sich durch das Produkt-„Bundling“ die Intransparenz und ggf. die Komplexität, so dass auch das Risiko für den Anleger steigt.

\section{b) Marktbereitung für die Honorarberatung}

Die von der MiFID II geplante Differenzierung zwischen abhängiger und unabhängiger Beratung wird zur Marktbereitung für die Honorarberatung beitragen, da die Regelungsvorschläge die Abgrenzungs- und Qualitätsmerkmale der Honorarberatung (Unabhängigkeit von Provisionszahlungen, umfassende und neutrale Marktanalyse) gesetzlich verankern. Ein höherer Marktanteil der Honorarberatung ${ }^{270}$ würde einen Wettbewerbsdruck erzeugen, der sich auch auf die Qualität der provisionsbasierten Anlageberatung positiv auswirken könnte. Die Notwendigkeit unabhängiger Beratung wurde in anderen Rechtsbereichen bereits erkannt; $\$ 60$ Abs. 2 VVG schreibt Versicherungsberatern vor, auf eine lediglich eingeschränkte Produktauswahl hinzuweisen. In Großbritannien wurden Provisionszahlungen für den Vertrieb von PRIP generell untersagt, und es muss angegeben werden, ob die Beratung auf Basis breiter Marktanalyse oder nur eingeschränkter Produktauswahl er-

267 Koch, aaO (Fn. 156), 485, 488.

268 Vgl. Косн, BKR 2012, 485, 489. Zur Rechtfertigung unterschiedlicher Beratungsstandards unter Bezugnahme auf die Komplexität und das Risiko des Produkts auch OLG Köln, Urt. v. 18.1.2012, BKR 2012, 203, 206; KLEEFELD, GWR 2012, 113; in erster Linie auf den Risikograd des Produkts stellen ab KLÖHN, ZIP 2011, 762, 764 f, sowie Wiechers, WM 2012, 477, 480.

269 Zu dessen Bewertung Möllers/Wenninger, NJW 2011, 1697, $1699 \mathrm{f}$.

270 Hierzu auch Möllers, FS Hopt, S. 2147, 2253 unter Hinweis auf Krohn, FAZ v. 25.7.2009, S. 9; eine Ausdehnung fordernd etwa die quirin bank, FAZ v. 8.11.2009, S. 15, ebenso Habschick/Evers, aaO (Fn. 151), S. 152. Gegenwärtig fristet die Honorarberatung in Kontinentaleuropa noch ein Nischendasein, nur 16-18\% der Kunden nehmen die Dienste unabhängiger Berater in Anspruch, vgl. Kommission, aaO (Fn. 82), S. 190 m. w. N. 
folgt. ${ }^{271}$ Im Lichte des Honoraranlageberatungsgesetzes ist jedoch zweifelhaft, ob der deutsche Gesetzgeber von der europäischen Gestaltungsoption Gebrauch macht und Zuwendungen generell untersagt. Wünschenswert wäre es, schließlich unterbindet nur ein generelles Verbot wirksam die von Provisionszahlungen ausgehenden Fehlanreize für die Anlageberatung. ${ }^{272}$

\section{c) Regulierung der Beratervergütung}

Anlageberatung ist zeit- und kostenintensiv, die Kundenberater stehen unter erheblichem Provisionsdruck. Erwartungsgemäß dürfte dem Kunden oftmals das Produkt mit der höchsten Provisionszahlung empfohlen werden, nicht zwangsläufig das zugleich bestgeeignete. ${ }^{773}$ Die Vorschläge zur Entkoppelung der Vergütungs- und Beurteilungssysteme vom Umsatz sind zu begrüßen, es gilt aber die weitere Ausgestaltung des bislang abstrakten Regelungskonzepts abzuwarten.

\section{d) Anbieter- und Beraterregulierung}

Als sinnvoll sind die geplanten Anforderungen an die Leitungsorgane und insbesondere die Kundenberater zu bewerten. Erhöhte Organisationspflichten und erforderliche Sachkundenachweise dienen nicht nur der Verbesserung der aufsichtsrechtlichen Compliance. Die hiermit einhergehende Professionalisierung bewirkt unmittelbar auch eine Qualitätsverbesserung der Anlageberatung.

271 FSA, Factsheet for Financial Advisers, Adviser Charging, abrufbar unter http://www.fsa.gov.uk/smallfirms/your_firm_type/financial/pdf/rdr_adviser.pdf S.2: „Advisers will need to discuss up-front how they will be paid and agree it with their client, rather than by being paid commission set by product providers.“; s. auch MoLONEY, 13 EBOR 169, 190 (2012).

272 So die Begründung für das britische Provisionsverbot beim PRIP-Vertrieb, vgl. FSA, Factsheet for Financial Advisers, aaO (Fn.271), S.2. Kritisch MülberT, ZHR 177 (2013), 160, 192.

273 Hierzu folgende Modellrechnung: Allein die 130.000 Sparkassen-Berater sollen durch den Verkauf von Finanzprodukten $10 \mathrm{Mrd}$. Euro pro Jahr erlösen müssen. Bei geschätzten 100.000 Kundenberatungen pro Tag (25 Mio. Gesprächen jährlich) müssten sie pro Beratungsgespräch durchschnittlich 400 Euro erlösen. Geht man zudem davon aus, dass von zehn Beratungsgesprächen nur zwei zum Abschluss führen, erhöht sich der pro Kunde zu erzielende Provisionsbetrag auf 2.000 Euro. S. FAZ v. 21.11.2012, S. 23. Die Zahlen werden genannt von Karl Matthäus Schmidt, Vorstandsvorsitzender der quirin bank, unter Verweis auf Angaben des ehemaligen Sparkassenpräsident Heinrich Haasis im Jahr 2010. 


\section{e) Anlegerleitbild: der schutzbedürftige, aber eigenverantwortlich bandelnde Anleger}

Dem Konzept der anlegerbezogenen Beratung liegt das Leitbild eines Anlegers zugrunde, der zwar erhöht schutzbedürftig ist, weil er vor sich selbst und vor Interessenkonflikten der Finanzintermediäre geschützt werden muss. Er ist aber dennoch in der Lage, eigenverantwortliche Investitionsentscheidungen zu treffen. Die Vorschaltung des Anlageberaters zur Informationsfilterung und Auswahl geeigneter Produkte bewirkt grundsätzlich einen wirksamen Schutz des Anlegers vor Fehlentscheidungen, wenn er zugleich vor Interessenkonflikten des Beraters geschützt wird. Die Ausrichtung der zu erteilenden Informationen an der individuellen Sachkenntnis und den Erfahrungen des Anlegers sowie die notwendige Erteilung einer Anlageempfehlung verdeutlichen indes, dass der Kunde ohne eine entsprechende Anlageberatung nach Auffassung des Gesetzgebers nicht in der Lage wäre, eine selbstständige rationale Anlageentscheidung zu treffen. Insbesondere bei „komplexen“ Anlageprodukten bedarf der Anleger hiernach der Hilfestellung eines Finanzintermediärs. ${ }^{274}$

\section{Professionelle Vermögensverwaltung}

\section{Regelungsziel}

Bei der professionellen Vermögensverwaltung trifft der Vermögensverwalter anstelle des Anlegers die einzelnen Anlageentscheidungen. ${ }^{275}$ Die Vermögensverwaltung kann einerseits als Portfoliomanagement ( $\$ 31$ Abs. 4 Satz 1 Alt. 2 WpHG), andererseits auch kollektiv für eine Vielzahl von Anlegern durch Investmentfonds erfolgen. ${ }^{276}$ Auf die fondsgebundene Vermögensverwaltung kann aus Platzgründen nur am Rande eingegangen werden. ${ }^{277}$ Grundsätzlich verursacht die Vermögensverwaltung Kosten und ist nur sinnvoll, wenn der geschaffene Mehrwert die Kosten übersteigt. ${ }^{278}$ Anlagerisiken sind durch Diversifikation zu minimieren und die Vermögensverwaltung muss produktiv sein, ${ }^{279}$ Ziele der Vermögensverwaltung sind also die Vermögenssicherung und Vermögensmehrung. ${ }^{280}$

275 Vgl. $\$ 2$ Abs. 3 Nr.7 WpHG: „Verwaltung in Finanzinstrumenten angelegter Vermögen mit Entscheidungsspielraum“.

276 S. Lenenbach, aaO (Fn. 8), Rdn. 8.1. S. Sethe, aaO (Fn. 207), S. 62.

277 Hierzu aber bspw. Möllers/Harrer/Krüger, WM 2011, 1537, $1539 \mathrm{ff}$.

278 Benicke, Wertpapiervermögensverwaltung, 2006, S. 99.

279 S. Benicke, aaO (Fn. 278), S. $764 \mathrm{ff}$.

280 Vgl. Benicke, aaO (Fn. 278), S. 129. 


\section{Instrumente}

\section{a) Informationen}

Da die konkrete Anlageentscheidung dem Vermögensverwalter überlassen bleibt, zielen die Informationen bei der Vermögensverwaltung nicht auf eine rationale Anlageentscheidung ab. Vielmehr sollen die geschuldeten Informationen dem Anleger vor Vertragsschluss die Entscheidung für oder gegen diese Form der Geldanlage und nach Vertragsschluss die ex post-Kontrolle des Verwalters ermöglichen. ${ }^{281}$

\section{b) Qualitätskontrolle}

Im Bereich der Fond gab es für Kapitalanlagegesellschaften schon immer die Depotbank und künftig die Verwahrstelle, welche die Kapitalanlagegesellschaft kontrolliert und Ansprüche für den Anleger geltend macht. ${ }^{282}$ Das geplante Kapitalanlagesetzbuch (KAGB) erhöht nun diesen Schutz noch, indem erstmals ein Bewerter das Vermögen der Gesellschaft regelmäßig prüfen muss, $\mathbb{S} 212 \mathrm{ff}$ KAGB-E. Für das Portfoliomanagement, also die klasssische Vermögensverwaltung bestehen nur die bereits erläuterte Qualitätskontrolle durch die unternehmensinterne Compliance und die BaFin, $\mathbb{S} \$ 33,35$ und 36 WpHG. ${ }^{283}$ Anders als für Anlageberater sind für die Vermögensverwaltung aber keine Pflichten zum Sachkundenachweis und zur Registrierung vorgesehen.

\section{c) Verbote}

Verbote gibt es im Investmentrecht im persönlichen und sachlichen Anwendungsbereich. Mit dem Prinzip der Risikodiversifizierung ( $\$ 1$ Satz 2 InvG), dem Numerus clausus der Fondstypen $\left(\mathbb{\int} 30 \mathrm{ff}\right.$ InvG) und dem Prinzip der Fremdverwaltung soll das Risikopotential dieser Anlageklasse begrenzt werden. Nach dem geplanten KAGB dürfen Spezial-AIF nicht von Kleinanlegern erworben werden, $\mathbb{\$} 1$ Abs. 6, Abs. 19 Nrn. 28 und 29 KABG-E.

281 Hierzu Sethe, aaO (Fn. 207), 912 ff. Zur vorvertraglichen Aufklärung $\ 5$ Abs. 2 Nr. 2 WpHG, zur ex post-Kontrolle s. $\$ 31$ Abs. 8 WpHG.

$282 \int \mathbb{S} 27 \mathrm{f}$ InvG und künftig $\int \mathbb{S} 76 \mathrm{f}, 83,86 \mathrm{KAGB}-\mathrm{E}$.

283 S. oben II.2.c)aa) und bb). 


\section{d) Zum Umgang mit Interessenkonflikten}

Der Kommissionsentwurf zur MiFID II sieht eine erhebliche Verschärfung des bestehenden Provisionsverbots ( $\$ 31 \mathrm{~d}$ WpHG) vor. Bei der Portfolioverwaltung soll jegliche Provisions- oder Vorteilsannahme untersagt werden. ${ }^{284}$ Demgegenüber will das EU-Parlament von einem generellen Provisionsverbot absehen ${ }^{285}$ und die Offenlegungspflicht lediglich dahingehend ergänzen, dass alle gezahlten oder empfangenen Anreize regelmäßig offengelegt werden müssen. ${ }^{286}$ Wie schon bei der Anlageberatung sollen die Mitgliedsstaaten Provisionszahlungen weiter einschränken oder ganz untersagen ${ }^{287}$ bzw. die Provisionsweitergabe an den Anleger verlangen können. ${ }^{288}$ Noch umfangreicher ist die Regelung von Interessenkonflikten durch die AIFM-Richtlinie. Das Risiko- und Portfoliomanagement ist voneinander zu trennen. Es gibt Regelungen zur Vergütung. ${ }^{289}$ Zudem muss die Depotbank unabhängig vom AIFM sein. ${ }^{290}$ Im Vergleich zur Vermögensverwaltung ist die Regulierung stärker; dies erscheint sinnvoll, weil die Fondsverwaltung keine individuelle Vermögensverwaltung darstellt, welche einzelne Kundenwünsche berücksichtigen kann.

Soweit die Portfolioverwaltung unabhängig erfolgt, sollen die Portfolioverwalter im Zuge der MiFID II dazu verpflichtet werden, die am Markt erhältlichen Finanzinstrumente umfassend zu berücksichtigen und sich nicht nur auf ihnen nahestehende Anbieter zu beschränken. ${ }^{291}$ Für unabhängige Portfolioverwalter ist ein generelles Provisionsverbot vorgesehen. ${ }^{292}$

\section{Bewertung}

\section{a) Regelungskonzept}

Für die MiFID II-Vorschläge zur Vermeidung von Interessenkonflikten gilt die vorherige Bewertung entsprechend: Provisionsverbote sind ebenso wie die Honorar-Portfolioverwaltung zu begrüßen, da hierdurch Interessenkonflikte wirksam eingedämmt werden. Allerdings fallen im Fondbereich regelmäßige Verwaltungsgebühren an und die klassische Vermögensverwaltung steht auf-

284 Art. 24 Abs. 6 MiFID II-E (Fn. 3).

285 Art. 24 Abs. 1 c, 5 i.d. F. MiFID II-E (EUP) (Fn. 4).

286 Art. 24 Abs. 6 Satz 1 MiFID II-E (EUP) (Fn. 4).

287 Art. 24 Abs. 5 Satz 1 MiFID II-E (EUP) (Fn. 4).

288 Art. 24 Abs. 1 c Satz 2, Abs. 5 Satz 2 MiFID II-E (EUP) (Fn. 4).

$289 \rrbracket 37$ KAGB-E.

290 Möllers/Harrer/Krüger, WM 2011, 1537, 1539.

291 Art. 24 Abs. 5 a Satz 1 MiFID II-E (EUP) (Fn. 4).

292 Art. 24 Abs. 5 a Satz 2 MiFID II-E (EUP) (Fn. 4). 
grund der geforderten Mindestanlagesummen ${ }^{293}$ nur einer absoluten Minderheit vermögender Privatanleger offen. Dass dieser Service zum Teil mit überzogenen Verwaltungsgebühren erkauft wird, steht ohnehin auf einem anderen Blatt.

\section{b) Anlegerleitbild: der schutzbedürftige Anleger mit reduzierter Eigenverantwortlichkeit}

Bei der professionellen Vermögensverwaltung beschränkt sich die erforderliche Mitwirkung des Anlegers und damit dessen Eigenverantwortlichkeit auf die Auswahl des geeigneten Vermögensverwalters oder Fonds. Die Fondsauswahl wird idealtypisch erleichtert, wenn der Anleger auf die Dienstleistung der Anlageberatung zurückgreifen kann. Im Anschluss an diese grundlegenden Entscheidungen ist lediglich die Überwachung der im jeweiligen Berichtszeitraum erzielten Performance erforderlich. Nach dem gesetzgeberischen Leitbild ist der Anleger jedoch zumindest dazu fähig, ggf. erforderliche Korrekturen durch Wechsel des Vermögensverwalters oder Fonds eigenverantwortlich vorzunehmen. Im Übrigen wird der Anleger vor dem Problem des information overload, dem Risiko von Fehlentscheidungen und Interessenkonflikten wirksam abgeschirmt: Er muss selbst keine Anlageentscheidungen treffen und die Informationsüberflutung stellt für den Verwalter aufgrund dessen professioneller Kenntnisse ein deutlich geringeres Risiko dar. Der Verwalter ist zudem an die definierten Anlagerichtlinien gebunden. Der erhöhten Schutzbedürftigkeit der Anleger wird im Fondsbereich dadurch Rechnung getragen, dass vom Gesetzgeber als riskant bewertete Anlageklassen wie Hedgefonds für Privatanleger nicht zugänglich sind.

\section{Zusammenfassende Thesen}

1.a) Dem Ziel der Anlegergleichbehandlung dienen zum einen marktbezogene Informationen, die sich an die Anlegergesamtheit richten, zum anderen kompensatorische Gleichbehandlungspflichten. Die Informationen werden einer dreistufigen Qualitätskontrolle durch die Emittenten selbst, durch die Aufsichtsbehörden und Dritter sowie den Markt unterzogen. Je umfangreicher diese ex-ante-Kontrolle ausfällt, desto geringer ist das Bedürfnis für zusätzliche Sanktionen ex post. Individueller Schadensersatz wird daher nur vereinzelt gewährt.

293 So nennt Lenenbach, aaO (Fn. 8), Rdn. 8.3., für die „standardisierte“ Vermögensverwaltung die Mindestanlagesumme von 100.000 Euro, die individuelle Vermögensberatung beginne ab einem Mindestkapital von 1 Mio. Euro. 
1.b) Dem Leitbild des kapitalmarktrechtlichen Informationsmodells lag über lange Zeit die Vorstellung vom Homo oeconomicus zugrunde. Der Gesetzgeber geht davon aus, dass dieser alle verfügbaren Informationen zur Kenntnis nimmt, bevor er eine Anlageentscheidung trifft. Anderenfalls versagt ihm der Gesetzgeber den Schutz. Neue Pflichten, die zunehmend auf die bessere Verständlichkeit der Marktinformationen abzielen, deuten auf einen Leitbildwandel zum „Homo oeconomicus light“ hin. Geschützt wird somit nur der „verständige" Anleger, dessen Fähigkeiten jedoch regelmäßig über denen des durchschnittlichen Privatanlegers liegen. Privatanleger sind deshalb oft auf Finanzintermediäre angewiesen, welche die Kapitalmarktinformation aufbereiten.

2.a) Umso wichtiger ist es daher, bestehende Schutzdefizite bei der Finanzintermediation regulatorisch anzugehen. Dabei lässt sich differenzieren: Nimmt der Anleger Anlage- oder professionelle Vermögensberatung in Anspruch, erhält er zwar professionelle Unterstützung. Er ist aber vor Interessenkonflikten des Intermediärs zu schützen.

2.b) Wenn (Klein-)Anleger diese kostenintensive Dienstleistung nicht wahrnehmen, sind sie besser als bisher vor unüberlegten Entscheidungen und riskanten Produkten zu schützen. So sollte der Gesetzgeber für Anlageentscheidungen ohne unterstützende Anlageberatung de lege ferenda ein generelles Schriftformerfordernis einführen. Zudem hat er Finanzprodukte stärker zu regulieren. Die Vorstöße der MiFID II zu Produkt-Prüfverfahren vor Markteinführung und ex ante-Interventionsrechten sind daher zu begrüßen. Der hiermit einhergehende Eingriff in die Marktfreiheit ist auch verhältnismäßig, weil hierdurch die Entscheidungsfreiheit des Anlegers sichergestellt wird.

2.c) Die standardisierte Kundeninformation durch die MiFID I zu ermöglichen, bedeutete einen Rückschritt für den Anlegerschutz. Dass die Standardisierung im Zuge der MiFID II wieder zur Disposition der Mitgliedsstaaten gestellt werden soll, ist daher positiv zu bewerten. Im Übrigen ist die Leistungsfähigkeit des Informationsmodells ausgereizt. Anlegerschutzdefizite resultieren nicht aus einem unzureichenden Informationsmodell oder dessen ungenügender Umsetzung durch die Wertpapierfirmen, sondern aufgrund des information overload sind der Informationseffizienz natürliche Grenzen gesetzt. Aus diesem Grund würde auch eine weitergehende Qualitätskontrolle

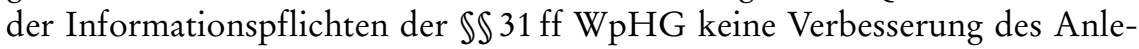
gerschutzes bewirken.

3.a) Das Verhältnis von europäischem und nationalem Recht wurde durch EuGH geklärt; die MiFID I zielt nicht auf eine Vollharmonisiserung des Zivilrechts $\mathrm{ab}$ und ist daher auch nicht im Wege richtlinienkonformer Auslegung auf der Ebene des nationalen Zivilrechts zu berücksichtigen. Weiterhin höchtrichterlicher Klärung bedarf indes das Verhältnis der WpHG - und der zivilrechtlichen Pflichten zueinander. 
3.b) Grundsätzlich reicht es nicht aus, Interessenkonflikte offenzulegen. Stattdessen sollte der deutsche Gesetzgeber von seiner Gestaltungsoption Gebrauch machen und den Anwendungsbereich des Honoraranlageberatungsgesetzes erweitern und jegliche Vorteilsgewährung an die Finanzintermediäre untersagen. Dies entspräche dem englischen Recht. Die MiFID II-Vorschläge bewirken zumindest die Marktbereitung für die Honorarberatung und erscheinen neben der Regulierung der Beratervergütung als Mindestvoraussetzung, um Interessenkonflikte bei der Anlageberatung besser als bisher in den Griff zu bekommen.

3.c) Die Qualität der Anlegerberatung bedingt sich insbesondere durch die Qualifikation des Beraters. Aus diesem Grund sind weitergehende Kontrollen der Mitarbeiterqualifikation sinnvoll, da sie zur Professionalisierung der Anlageberatung beitragen.

4.a) Bei der Vermögensverwaltung übernimmt der Verwalter die Anlageentscheidung. Informationen dienen deshalb nicht dazu, eine optimale Anlegerentscheidung zu ermöglichen, sondern im Vorfeld der Auswahl und dann der Kontrolle des Verwalters.

4.b) Auch hier wird die Qualitätskontrolle durch Dritte intensiviert, im Investmentrecht durch die Kontrolle durch Dritte, etwa die Depotbank, jetzt auch durch den Bewerter und bestimmte Verbote. Im Rahmen der klassischen Vermögensverwaltung fehlt bisher aber eine Kontrolle durch Dritte.

5.) Das Anlegerleitbild des Gesetzgebers wird vom jeweiligen Regelungszweck bestimmt. Ein einheitliches Anlegerleitbild lässt sich aus diesem Grund nicht feststellen. Allen Anlegerleitbildern liegt die Annahme zugrunde, dass der Anleger rationale, eigenverantwortliche Entscheidungen treffen kann. Am stärksten gilt das Paradigma der Anlegerrationalität im Bereich der marktbezogenen Informationspflichten („Homo oeconomicus light“). Sobald der Anleger die Dienstleistungen eines Finanzintermediärs in Anspruch nimmt, tritt das Rationalitätsparadigma zugunsten eines erhöhten Schutzregimes zurück. Die geringsten Anforderungen an die Fähigkeiten des Anlegers bestehen im Rahmen professioneller Vermögensverwaltung bzw. im Fondbereich. Diese der Abstufung der überantworteten Eigenverantwortlichkeit folgende Ausgestaltung des Anlegerleitbilds erscheint sinnvoll. Schließlich wäre eine vollständige Risikofreistellung des Anlegers mit der Tatsache nicht vereinbar, dass die Geldanlage als Vertrauensgut am Kapitalmarkt auf reinen Exspektanzen beruht, die aufgrund ihrer Ungewissheit stets eine gewisse Risikobereitschaft des Anlegers erfordern. 